Check for updates

Cite this: Mater. Chem. Front., 2019, 3, 2090

\title{
A novel ordered hollow spherical nickel silicate- nickel hydroxide composite with two types of morphologies for enhanced electrochemical storage performance $\uparrow$
}

\author{
Qiushi Wang, Yifu Zhang, (D) * Jinqiu Xiao, Hanmei Jiang, Xiaojuan Li and \\ Changgong Meng (D)
}

\begin{abstract}
Herein, a facile strategy was developed for the preparation of a nanostructured nickel silicate-nickel hydroxide composite $\left(\mathrm{NiSi}-\mathrm{Ni}(\mathrm{OH})_{2}\right)$ with two types of morphologies, including coated hollow nanospheres ( $\left.\mathrm{NiSi} @ \mathrm{Ni}(\mathrm{OH})_{2}\right)$ and platelet-assembled hollow spheres $\left(\mathrm{Ni}(\mathrm{OH})_{2}-\mathrm{Si}\right)$ as a positive electrode material in hybrid supercapacitors. This strategy involved the use of nano-sized $\mathrm{SiO}_{2}$ derived from the Stöber method as the silicon source and a single-step hydrothermal method. The as-synthesized $\mathrm{NiSi}-\mathrm{Ni}(\mathrm{OH})_{2}$ composite exhibited a battery-like redox behavior and relatively high charge storage property (476.4 $\mathrm{F} \mathrm{g}^{-1}$ at $2 \mathrm{~A} \mathrm{~g}^{-1}$ ) when measured in a three-electrode system. It also delivered high stability during long-term cycling (103.3\% after 10000 cycles), which is mainly due to the synergistic effect after the combination of the two materials, where the hollow spherical structures facilitate the fast diffusion of electrolyte ions and enable the fast transmission of electrons. Considering its practical applications, a hybrid asymmetric supercapacitor $(\mathrm{HSC})$ device was assembled using $\mathrm{NiSi}-\mathrm{Ni}(\mathrm{OH})_{2}$ as the positive electrode and porous activated carbon as the negative electrode in PVA-KOH electrolyte gel. The HSC exhibited a capacitance of $674.7 \mathrm{mF} \mathrm{cm}^{-2}$ at $2 \mathrm{~mA} \mathrm{~cm}^{-2}$, corresponding to a maximum energy and power density of $21.6 \mathrm{~W} \mathrm{~h} \mathrm{~kg}^{-1}\left(5.2 \mathrm{~W} \mathrm{~h} \mathrm{~cm}^{-3}\right)$ and $431.7 \mathrm{~mW} \mathrm{~kg}^{-1}\left(104.3 \mathrm{~mW} \mathrm{~cm}{ }^{-3}\right)$, respectively. These properties demonstrate the potential of the hollow-structured $\mathrm{NiSi}-\mathrm{Ni}(\mathrm{OH})_{2}$ composite for achieving high-energy and stable energy storage systems.
\end{abstract}

Received 17th June 2019,

Accepted 30th July 2019

DOI: $10.1039 / c 9 q m 00392 d$

rsc.li/frontiers-materials and pseudocapacitors. In EDLCS, the charges are separated on the interface between the electrode and electrolyte to form a Helmholtz double layer, by which electricity is stored. However, the most widely commercially used EDLC material, i.e., active carbon, possesses a limited theoretical capacitance, which can hardly satisfy the growing demand for high-energy storage electronic devices. In contrast, pseudocapacitors/battery-like materials store electricity via the transformation of electrons. Specifically, their energy storage ability originates from the redox reaction caused by the charge transfer. The typical pseudocapacitors/ battery-like materials (include metal oxides/nitrides/sulfides and conducting polymers) offer relatively high energy densities (3-4 times that of EDLCs), and thus have attracted significant attention in recent years..$^{8-11}$ For example, typical transition metal oxides and their corresponding transition metal hydroxides, such as $\mathrm{RuO}_{2}, \mathrm{NiO}_{x}, \mathrm{Ni}(\mathrm{OH})_{2}, \mathrm{VO}_{x}, \mathrm{CoO}_{x}, \mathrm{Co}(\mathrm{OH})_{2}$, and $\mathrm{MnO}_{2}$, have considerable theoretical capacitances. ${ }^{12-24}$ However, their practical application is still hindered by their low inherent conductivity and serious pulverization during the long-term cycling process. Consequently, these electrode materials usually suffer from poor rate performance and rapid capacity fading in 
the cycling process. Among them, nickel hydroxide $\left(\mathrm{Ni}(\mathrm{OH})_{2}\right)$ with the battery-type behavior is one of the most promising candidates due to its high theoretical capacitance of $2082 \mathrm{~F} \mathrm{~g}^{-1} \cdot{ }^{25,26}$ However, its practical application in supercapacitors is still limited by its unsatisfied conductivity, which has triggered many studies focusing on the combination of $\mathrm{Ni}(\mathrm{OH})_{2}$ and conductive carbon. ${ }^{27,28}$

The hollow structure of electrode materials has been widely studied in the water-spitting, electrochemical catalyst and energy storage areas. ${ }^{29-33}$ Owing to this special structure, the stress-induced structural variation during long-term electrochemical reactions can be effectively alleviated. ${ }^{34}$ Specifically, the hollow structure facilitates electrolyte transmission and ion diffusion, prolonging the stability of nanocomposites during electrochemical reactions. ${ }^{35,36}$ Recently, hollow structured metal silicates (such as manganese silicate and copper silicate) have successfully attracted attraction from researchers due to their excellent electrochemical activities when applied as battery materials. ${ }^{37-40}$ The metal silicates synthesized in this approach possess the merits of easy-preparation, large surface area, diverse surface morphologies and unique electrochemical properties owing to the different metal elements involved. ${ }^{9,41-45}$ However, to the best of our knowledge, no reports have focused on the application of metal silicate-metal hydroxide composites as positive electrode materials in supercapacitor materials. Considering the advantageous properties of hollow structure metal silicates, an enhanced energy storage performance can be achieved.

In this work, we demonstrate an easy-operation and novel method for the effective preparation of a nickel silicate-nickel hydroxide composite $\left(\mathrm{NiSi}-\mathrm{Ni}(\mathrm{OH})_{2}\right)$, which consists of two morphologies, coated hollow nanospheres (named NiSi@Ni $\left.(\mathrm{OH})_{2}\right)$ and platelet-assembled nanospheres (named $\mathrm{Ni}(\mathrm{OH})_{2}-\mathrm{Si}$ ). This strategy involves the use of nano-sized $\mathrm{SiO}_{2}$ as a template, and subsequent hydrothermal treatment. The nickel silicate and nickel hydroxide composition could be precisely controlled by simply changing the amount of nickel species added to the reaction systems. Furthermore, the electrochemical performance of the obtained samples as positive electrode materials in supercapacitors was evaluated. The synergistic effect achieved by combining nickel silicate and nickel hydroxide resulted in an excellent capacitance and superb cycling performance, which alleviated the problem of the poor cycling performance of nickel hydroxide. By calculating and managing the proportion of the two components, the optimum product ( $\left.\mathrm{NiSi}-\mathrm{Ni}(\mathrm{OH})_{2}-4\right)$ exhibited an excellent capacity (476.4 $\mathrm{F} \mathrm{g}^{-1}$ at $\left.2 \mathrm{~A} \mathrm{~g}^{-1}\right)$, good rate performance, and remarkable cyclic stability $(103.3 \%$ after 10000 cycles). Furthermore, an asymmetric capacitor device was assembled using $\mathrm{NiSi}-\mathrm{Ni}(\mathrm{OH})_{2}$ and activated carbon, which exhibited extraordinary energy storage potential.

\section{Experimental}

\subsection{Material preparation}

Tetraethyl orthosilicate (TEOS), nickel(II) chloride hexahydrate $\left(\mathrm{NiCl}_{2} \cdot 6 \mathrm{H}_{2} \mathrm{O}\right)$, nickel nitrate hexahydrate $\left(\mathrm{Ni}\left(\mathrm{NO}_{3}\right)_{2} \cdot 6 \mathrm{H}_{2} \mathrm{O}\right)$, $\mathrm{NH}_{4} \mathrm{Cl}, \mathrm{NH}_{3} \cdot \mathrm{H}_{2} \mathrm{O}$ and ethanol were purchased from Aladdin
Chemical Reagent Co., Ltd and used without further purification.

\subsection{Preparation of $\mathrm{NiSi}-\mathrm{Ni}(\mathrm{OH})_{2}$}

In a typical procedure, $\mathrm{SiO}_{2}$ spheres with an average diameter of $\sim 200 \mathrm{~nm}$ were prepared via a modified Stöber method. ${ }^{41}$ $0.1 \mathrm{~g} \mathrm{SiO}_{2}$ was dispersed in $20 \mathrm{~mL}$ deionized water under vigorous ultrasonication for $1 \mathrm{~h}$, which was labeled as solution A. A variable amount of $\mathrm{NiCl}_{2} \cdot 6 \mathrm{H}_{2} \mathrm{O}$ was added to $20 \mathrm{~mL}$ deionized water under vigorous stirring for $10 \mathrm{~min}$. Then, $10 \mathrm{mmol}$ of $\mathrm{NH}_{4} \mathrm{Cl}$ was added and stirred for $10 \mathrm{~min}$. Finally, $2 \mathrm{~mL} \mathrm{NH}_{3} \cdot \mathrm{H}_{2} \mathrm{O}$ was added to the solution for another $10 \mathrm{~min}$ to form solution B. Solution A and B were mixed by adding solution B dropwise to solution A. The mixture was vigorously stirred for $30 \mathrm{~min}$ and transferred to a Teflon-lined autoclave. After hydrothermal reaction at $120{ }^{\circ} \mathrm{C}$ for $24 \mathrm{~h}$, the green precipitate was washed with deionized water and ethanol three times. Finally, the obtained product was vacuum dried at $70{ }^{\circ} \mathrm{C}$ for $12 \mathrm{~h}$. The as-synthesized samples were named $\mathrm{NiSi}-\mathrm{Ni}(\mathrm{OH})_{2}-1$, $\mathrm{NiSi}-\mathrm{Ni}(\mathrm{OH})_{2}-2$, NiSi-Ni(OH $)_{2}-3$, NiSi-Ni(OH $)_{2}-4$ and $\mathrm{NiSi}-\mathrm{Ni}(\mathrm{OH})_{2}-5$, corresponding to an $\mathrm{Ni} / \mathrm{Si}$ ratio of $0.5 / 1,1 / 1,2 / 1,3 / 1$ and $4 / 1$, respectively. The amount of $\mathrm{Si}$ in $\mathrm{NiSi}-\mathrm{Ni}(\mathrm{OH})_{2}-1-5$ was determined to be $49 \%, 41 \%, 29 \%, 22 \%$ and $16 \%$, respectively, via ICP spectrometry. For comparison, pure $\mathrm{NiSiO}_{x}$ and $\mathrm{Ni}(\mathrm{OH})_{2}$ were also synthesized (ESI $\dagger$ ).

\subsection{Characterization}

The morphology and microstructure of the samples were determined via field emission scanning electron microscopy (FE-SEM, NOVA NanoSEM 450, FEI) and transmission electron microscopy (TEM, FEI Tecnai F30, FEI) together with selected area electron diffraction (SAED). The samples for SEM observation were sputtered for $90 \mathrm{~s}$ with gold to better obtain the morphology of the surface. The samples for TEM were dispersed in pure ethanol and sonicated for $15 \mathrm{~min}$. Then, the well-dispersed solution was dropped on a copper grid holder and introduced into the TEM chamber. The composition of the products was tested via energy-dispersive X-ray spectroscopy (EDS) and elemental mapping using a scanning electron microscope (FE-SEM, NOVA NanoSEM 450, FEI). The crystalline structure was characterized via X-ray diffractometry using a $\mathrm{Cu} \mathrm{K} \alpha$ X-ray source $(\lambda=1.5418 \AA)$ in the $2 \theta$ range of $4^{\circ}$ to $80^{\circ}$. Fouriertransform infrared spectra (FTIR) were observed using a Nicole Avatar 360 FTIR spectrometer (USA) in the range of $4000-400 \mathrm{~cm}^{-1}$, with the KBr disk method. The specific surface area was calculated using the Brunauer-Emmett-Teller (BET) method on a Micromeritics ASAP-2020 at a heating rate of $10{ }^{\circ} \mathrm{C} \mathrm{min}{ }^{-1}$, and the samples were degassed at $150{ }^{\circ} \mathrm{C}$ for $12 \mathrm{~h}$. X-ray photoelectron spectroscopy (XPS) was performed on an ESCALAB 250Xi electron spectrometer. The concentration of Si was measured via inductively coupled plasma-atomic emission spectroscopy (ICP-AES, Optima2000DV, PerkinElmer).

\subsection{Electrochemical measurements}

The electrochemical performance of the prepared products was characterized using a CHI 660E electrochemistry workstation 
(Shanghai, China) in the conventional three-electrode system. Cyclic voltammetry (CV), galvanostatic charge-discharge (GCD) and electrochemical impedance spectroscopy (EIS) analyses were performed using the as-prepared materials $\left(\mathrm{NiSi}-\mathrm{Ni}(\mathrm{OH})_{2}\right.$, $\mathrm{NiSiO}_{x}$ and $\mathrm{Ni}(\mathrm{OH})_{2}$ ) as the working electrode, carbon rod as the counter electrode and mercuric-oxide-electrode $(\mathrm{Hg}-\mathrm{HgO})$ as the reference electrode in $3 \mathrm{M} \mathrm{KOH}$ aqueous electrolyte. The working electrode was prepared by grinding $80 \mathrm{wt} \%$ of the as-prepared active materials, $10 \mathrm{wt} \%$ of polyvinylidene difluoride (PVDF) as a binder and $10 \mathrm{wt} \%$ of carbon black as a conductive additive in an agate mortar using an appropriate amount of $\mathrm{N}$-methyl-2-pyrrolidone (NMP) as the solvent. Then, the mixture slurry was smeared on nickel foam $\left(1 \mathrm{~cm}^{2}\right.$ active area) and dried in at $80{ }^{\circ} \mathrm{C}$ for $12 \mathrm{~h}$ to remove the organic solvent. The electrode was pressed at $10 \mathrm{MPa}$ to guarantee strong attachment between the active material and the Ni-grids. The typical mass loading of electrode material was estimated to be $3-5 \mathrm{mg} \mathrm{cm}^{-2}$. The mass capacitance $\left(\mathrm{F} \mathrm{g}^{-1}\right)$ of the as-prepared electrode materials in the three-electrode system was calculated from the GCD curves based on the following equation:

$$
C=(I \cdot \Delta t) /(m \cdot \Delta V)
$$

where, $C$ is the mass capacity $\left(\mathrm{F} \mathrm{g}^{-1}\right), I$ is the discharging current density $\left(\mathrm{A} \mathrm{g}^{-1}\right), \Delta t$ is the discharging time (s), $m$ is the active mass $(\mathrm{g})$ and $\Delta V$ is the discharging potential range $(\mathrm{V})$ of the single electrode.

The solid-state asymmetric hybrid supercapacitor (HSC) device was fabricated with $\mathrm{NiSi}-\mathrm{Ni}(\mathrm{OH})_{2}$ as the positive electrode and $\mathrm{AC}$ as the negative electrode, which was denoted as $\mathrm{NiSi}-\mathrm{Ni}(\mathrm{OH})_{2} / / \mathrm{AC}$. A filter separator (NKK separator) was used between the two electrodes to prevent a short circuit. Polyvinyl alcohol (PVA)/KOH gel was used as the electrolyte, which was prepared by adding $\mathrm{KOH}$ (4.26 g) and PVA (3.04 g) to $30 \mathrm{~mL}$ of deionized water and heating at $80{ }^{\circ} \mathrm{C}$ for $2 \mathrm{~h}$ under vigorous stirring. After the solution became clear and cool, the two electrodes together with the separator were soaked in the $\mathrm{PVA} / \mathrm{KOH}$ gel solution and assembled. Subsequently, the configuration was introduced into a polyethylene bag and sealed properly. To balance the charge storage, the mass values of the two electrodes were optimized based on the following equation before the assembly:

$$
m^{-} \times C^{-}=m^{+} \times C^{+}, \quad\left(Q^{-}=Q^{+}\right)
$$

where, $\mathrm{m}^{+}$and $\mathrm{m}^{-}$represent the mass loading of the active materials on the electrode, and $C^{+}$and $C^{-}$represent the areal capacitance of the electrode, respectively. The active area of both the negative and positive electrodes was $1.25 \mathrm{~cm} \times 0.8 \mathrm{~cm}$ in size. All electrochemical tests on the HSC device were performed in the two-electrode configuration at ambient temperature. The mass capacitance $\left(C_{\mathrm{m}}\right)$, areal capacitance $\left(C_{\mathrm{s}}\right)$ and volumetric capacitance $\left(C_{\mathrm{v}}\right)$ were calculated from the GCD curves using the following equations:

$$
\begin{gathered}
C_{\mathrm{m}}=I \Delta t / m \Delta V \\
C_{\mathrm{s}}=I \Delta t / s \Delta V \\
C_{\mathrm{v}}=I \Delta t / V \Delta V
\end{gathered}
$$

where, $I$ is the discharge current, $\Delta t(\mathrm{~s})$ is the discharge time, $\Delta V(\mathrm{~V})$ is the potential window, and $m, s$ and $V$ are the total active mass, total active area and total volume of the device, respectively.

The volume energy density $E_{\mathrm{v}}\left(\mathrm{mW} \mathrm{h} \mathrm{cm}^{-3}\right)$, mass energy density $E_{\mathrm{m}}\left(\mathrm{mW} \mathrm{h} \mathrm{kg}{ }^{-1}\right)$, equivalent volume power density $P_{\mathrm{v}}$ $\left(\mathrm{mW} \mathrm{cm}^{-3}\right)$ and mass power density $P_{\mathrm{m}}\left(\mathrm{mW} \mathrm{kg}^{-1}\right)$ of the device were obtained from the following equations:

$$
\begin{gathered}
E_{\mathrm{m}}=C_{\mathrm{m}} \Delta V^{2} / 2 \times 3600 \\
E_{\mathrm{v}}=C_{\mathrm{v}} \Delta V^{2} / 2 \times 3600 \\
P_{\mathrm{m}}=E_{\mathrm{m}} / \Delta T \\
P_{\mathrm{v}}=E_{\mathrm{v}} / \Delta T
\end{gathered}
$$

\section{Results and discussion}

The schematic diagram shown in Fig. 1 demonstrates the successful preparation of the $\mathrm{NiSi}-\mathrm{Ni}(\mathrm{OH})_{2}$ material. Initially, silicon dioxide spheres were prepared via a single-step hydrolysis process with the aid of $\mathrm{NH}_{3} \cdot \mathrm{H}_{2} \mathrm{O}$ using a modified Stöber

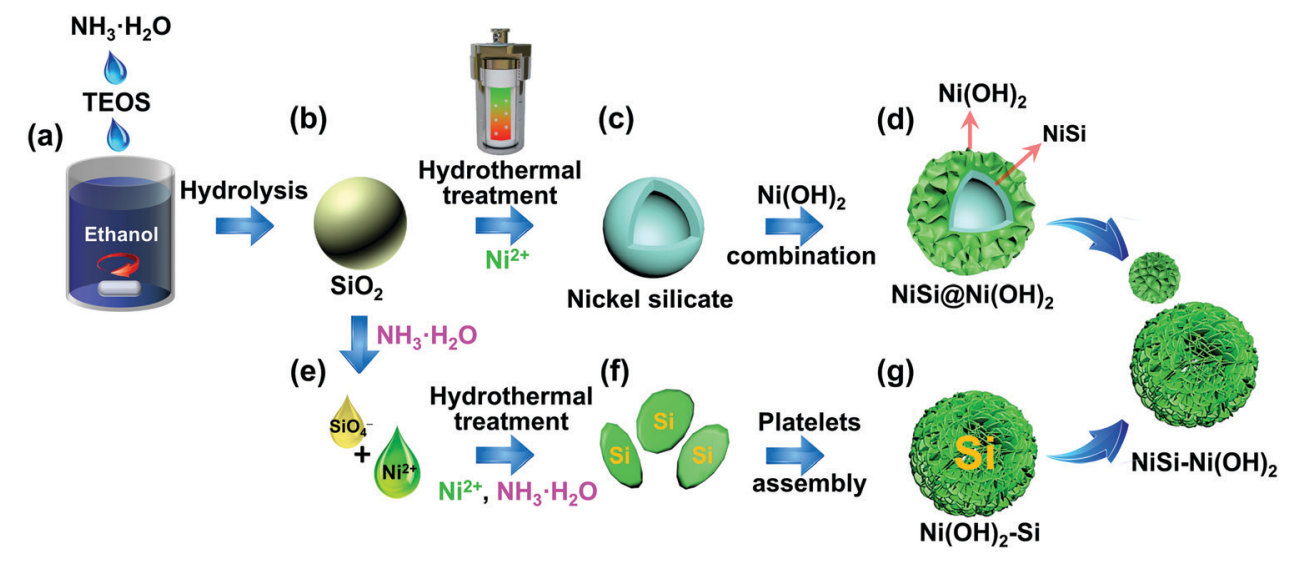

Fig. 1 Schematic illustrating the preparation of $\mathrm{NiSi}-\mathrm{Ni}(\mathrm{OH})_{2}$ samples using the Stöber and hydrothermal methods. 
method. As is well known, the template plays a critical role in the design and construction of the morphologies of nanocomposites. The advantages of the silicon spheres prepared using this method include their facile preparation, controllable size, smooth surface and spherical morphology. The chemical mechanism involved in the synthetic process of the $\mathrm{SiO}_{2}$ spheres can be clarified as follows: ${ }^{46,47}$

$$
\begin{aligned}
\mathrm{Si}\left(\mathrm{OC}_{2} \mathrm{H}_{5}\right)_{4(\mathrm{l})} & +4 \mathrm{H}_{2} \mathrm{O}_{(1)} \frac{\text { Suspension in ethanol }}{\mathrm{pH} 11-12\left(\mathrm{NH}_{3} \cdot \mathrm{H}_{2} \mathrm{O}\right)} \mathrm{Si}(\mathrm{OH})_{4} \\
& +4 \mathrm{C}_{2} \mathrm{H}_{5} \mathrm{OH}_{(\mathrm{l})}
\end{aligned}
$$

$$
\mathrm{Si}(\mathrm{OH})_{4} \frac{\text { Suspension in ethanol }}{\mathrm{pH} 11-12\left(\mathrm{NH}_{3} \cdot \mathrm{H}_{2} \mathrm{O}\right)} \text { nano- } \mathrm{SiO}_{2(\mathrm{Sol})}+2 \mathrm{H}_{2} \mathrm{O}_{(\mathrm{l})}
$$

Therefore, the $\mathrm{SiO}_{2}$ spheres used here could control the morphology of the product to a certain degree. The possible formation mechanism of NiSi-Ni(OH $)_{2}$ can be predicted as follows: firstly, the weak alkaline aqueous ammonia solution was selected as the base to provide hydroxide ions to react with $\mathrm{SiO}_{2}$. Simultaneously, the additive of $\mathrm{NH}_{4} \mathrm{Cl}$ plays a necessary role in regulating the $\mathrm{pH}$ of the solution during the formation of $\mathrm{NiSi}-\mathrm{Ni}(\mathrm{OH})_{2}$. When an adequate amount of $\mathrm{NH}_{4} \mathrm{Cl}$ is added, pure NiSiO is formed. However, when the content of $\mathrm{NH}_{4} \mathrm{Cl}$ is insufficient, a relatively high concentration of $\mathrm{NH}_{3} \cdot \mathrm{H}_{2} \mathrm{O}$ will convert the $\mathrm{SiO}_{2}$ spheres into silicate ions under alkaline conditions at a high temperature, as previously reported. ${ }^{39}$ Subsequently, $\mathrm{NiSi} @ \mathrm{Ni}(\mathrm{OH})_{2}$ and $\mathrm{Ni}(\mathrm{OH})_{2}$-Si are grown via two different pathways. For NiSi@Ni $(\mathrm{OH})_{2}$, the nickel silicate is in situ grown on the surface of the $\mathrm{SiO}_{2}$ spheres by nickel ions reacting with the $\mathrm{SiO}_{2}$ spheres, leading to the formation of hollow $\mathrm{NiSiO}_{x}$ shells. Then, $\mathrm{Ni}(\mathrm{OH})_{2}$ is coated on the surface of $\mathrm{NiSiO}_{x}$ via a hydrolysis reaction. For $\mathrm{Ni}(\mathrm{OH})_{2}-\mathrm{Si}$, the silica source originates from the silicon spheres reacted with hydroxide ions. Then, the hollow spherical nickel silicate-nickel hydroxide is generated by the dissolved silica ions reacting with the excess nickel ions and the hydrolysis reaction of nickel ions. The chemical mechanism involved in the synthesis of the $\mathrm{SiO}_{2}$ spheres can be clarified as follows: ${ }^{48}$

$$
2 \mathrm{NH}_{3} \cdot \mathrm{H}_{2} \mathrm{O}_{(\mathrm{aq})} \leftrightarrow 2 \mathrm{NH}_{4}^{+}{ }_{(\mathrm{aq})}+\mathrm{OH}^{-}(\mathrm{aq})
$$

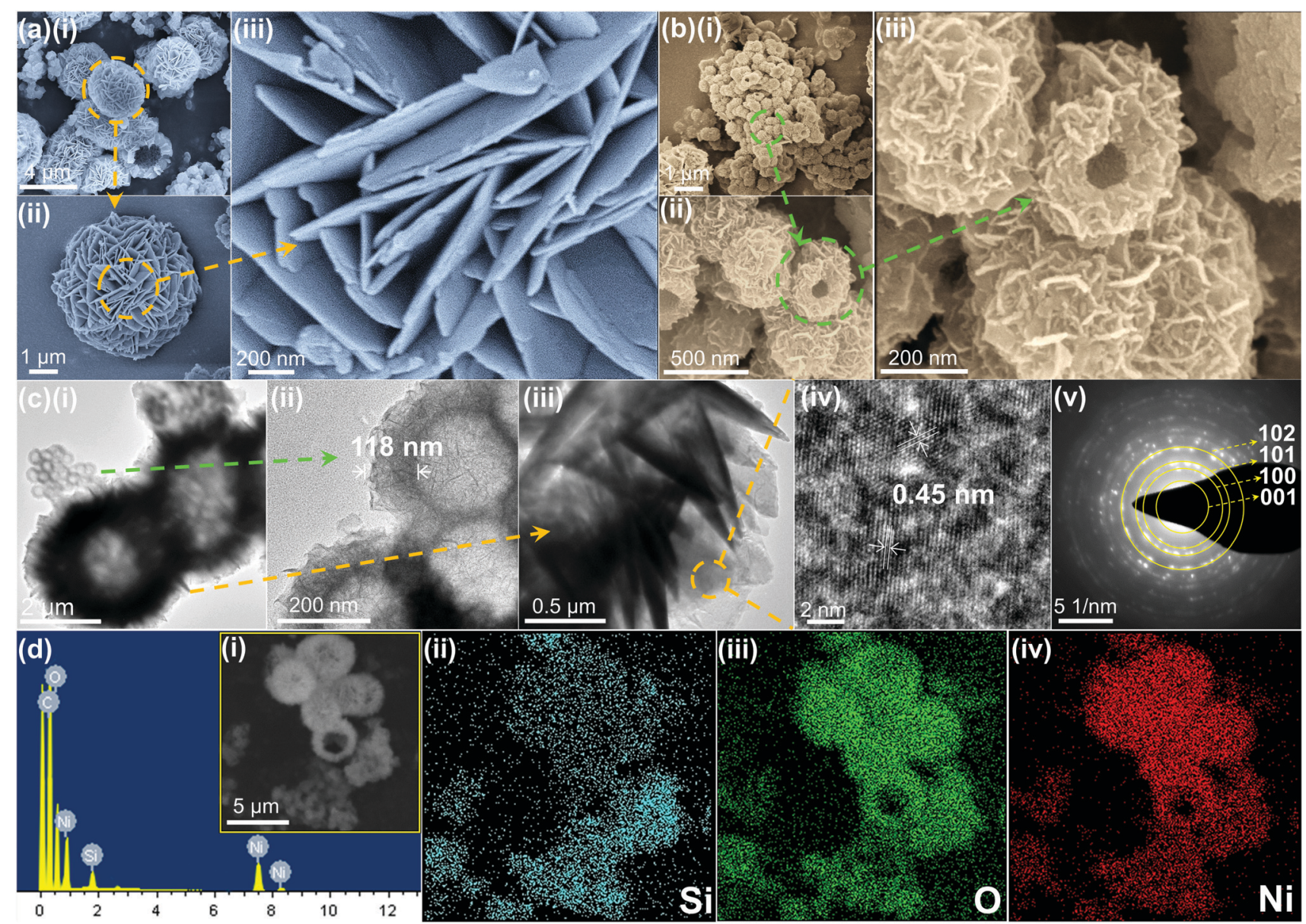

Fig. 2 (a-i-iii) Low- to high-magnification FE-SEM images of $\mathrm{Ni}(\mathrm{OH})_{2}-\mathrm{Si}$ in $\mathrm{NiSi}-\mathrm{Ni}(\mathrm{OH})_{2}-4$. (b-i-iii) FE SEM images of $\mathrm{NiSi}\left(\mathrm{Ni}(\mathrm{OH})_{2}\right.$ in $\mathrm{NiSi}-\mathrm{Ni}(\mathrm{OH})_{2}-4$. (c-i-iii) Low- to high-magnification FE SEM images of NiSi-Ni(OH $)_{2}-4$. (c-iv and v) HRTEM and SAED pattern of $\mathrm{Ni}(\mathrm{OH})_{2}-\mathrm{Si}$ in $\mathrm{NiSi}-\mathrm{Ni}(\mathrm{OH})_{2}-4$, respectively. (d-i) Selected SEM area and EDX spectrum of $\mathrm{NiSi}-\mathrm{Ni}(\mathrm{OH})_{2}-4$ and elemental mapping images of (d-ii) $\mathrm{Si}$, (d-iii) O and (d-iv) $\mathrm{Ni}$ elements in the product. 


$$
\begin{gathered}
\mathrm{SiO}_{2 \text { (amorphous) }}+4 \mathrm{OH}^{-}{ }_{(\mathrm{aq})} \rightarrow 2 \mathrm{SiO}_{3}{ }^{2-}{ }_{(\mathrm{aq})}+2 \mathrm{H}_{2} \mathrm{O}_{(\mathrm{l})} \\
2 \mathrm{SiO}_{3}{ }^{2-}{ }_{(\mathrm{aq})}+3 \mathrm{Ni}^{2+}{ }_{(\mathrm{aq})}+2 \mathrm{H}_{2} \mathrm{O}+2 \mathrm{OH}^{-}{ }_{(\mathrm{aq})} \rightarrow \mathrm{Ni}_{3} \mathrm{Si}_{2} \mathrm{O}_{5}(\mathrm{OH})_{4(\mathrm{~s})}
\end{gathered}
$$

$$
3 \mathrm{Ni}^{2+}(\mathrm{aq})+6 \mathrm{OH}^{-}(\mathrm{aq}) \leftrightarrow 3 \mathrm{Ni}(\mathrm{OH})_{2(\mathrm{~s})}
$$

The structure and surface morphology of the prepared samples were investigated via FE-SEM and TEM. For comparison, the pure $\mathrm{SiO}_{2}$ spheres, nickel hydroxide (abbreviated as $\left.\mathrm{Ni}(\mathrm{OH})_{2}\right)$ and nickel silicate (abbreviated as $\mathrm{NiSiO}_{x}$ ) were also tested. Fig. S1 (ESI $\dagger$ ) shows the morphologies of the $\mathrm{SiO}_{2}$ spheres, pure nickel hydroxide and nickel silicate. The $\mathrm{SiO}_{2}$ spheres exhibit diameters of around $200 \mathrm{~nm}$ and a solid core (Fig. S1a-c, ESI $\dagger$ ). $\mathrm{Ni}(\mathrm{OH})_{2}$ consists of numerous platelets aggregated and a rough surface (Fig. S1d-f, ESI $\dagger$ ). The TEM image (Fig. S1f, ESI $\dagger$ ) demonstrates that the nickel hydroxide has a hollow structure with a thickness of about $1.2 \mu \mathrm{m}$. $\mathrm{NiSiO}_{x}$ possesses a rambutan-like morphology with a diameter of around $180 \mathrm{~nm}$ (Fig. S1g-i, ESI $\dagger$ ). It also has a rough surface and uniform shell with a thickness of about $54 \mathrm{~nm}$. Fig. 2a shows the typical FE-SEM image of $\mathrm{NiSi-Ni(OH})_{2}-4$ prepared via the hydrothermal method. From the FE-SEM image, it can be observed that $\mathrm{NiSi}-\mathrm{Ni}(\mathrm{OH})_{2}-4$ possesses the nickel hydroxide-like spherical morphology (named $\mathrm{Ni}(\mathrm{OH})_{2}-\mathrm{Si}$ ) and nickel silicate-like spherical morphology (named NiSi@Ni(OH $)_{2}$ ). $\mathrm{Ni}(\mathrm{OH})_{2}$-Si exhibits a laminated flower-like morphology with an average diameter of $5 \mu \mathrm{m}$ (Fig. $2 \mathrm{a}$ (i-iii) and Fig. S2a, b, ESI $\dagger$ ). $\mathrm{NiSi@Ni(OH})_{2}$ possesses a nanosheets-assembled surface with an average diameter of $330 \mathrm{~nm}$ (Fig. 2b(i-iii) and Fig. S2d, e, $\mathrm{ESI} \dagger)$. Besides, both $\mathrm{Ni}(\mathrm{OH})_{2}$-Si and NiSi@Ni(OH)$)_{2}$ possess hollow spherical morphologies, which facilitate the diffusion of electrolyte and lead to fast redox electrochemical reactions. To further reveal the morphology of the samples, Fig. $2 \mathrm{c}(\mathrm{i}-\mathrm{v})$ and Fig. S2c, f (ESI $\dagger$ ) demonstrate the TEM analysis of $\mathrm{NiSi}-\mathrm{Ni}(\mathrm{OH})_{2}-4$. As shown in Fig. $2 \mathrm{c}(\mathrm{i})$, NiSi-Ni(OH $)_{2}-4$ is composed of $\mathrm{Ni}(\mathrm{OH})_{2}-\mathrm{Si}$ and $\mathrm{NiSi} @ \mathrm{Ni}(\mathrm{OH})_{2}$, which is inconsistent with the FE-SEM results. The individual TEM images of $\mathrm{Ni}(\mathrm{OH})_{2}-\mathrm{Si}$ and NiSi@Ni(OH $)_{2}$ are exhibited in Fig. 2c(ii, iii) and Fig. S2(c, f) $(\mathrm{ESI} \dagger)$, respectively. As shown in the TEM images, $\mathrm{Ni}(\mathrm{OH})_{2}$-Si shows the morphology of hollow spheres consisting of aggregated platelets, and NiSi@Ni(OH $)_{2}$ exhibits a morphology of hollow spheres with a thickness of about $118 \mathrm{~nm}$, which is thicker than that of pure $\mathrm{NiSiO}_{x}$. The additional thickness in NiSi@Ni(OH $)_{2}$ proves that $\mathrm{Ni}(\mathrm{OH})_{2}$ was successfully coated on NiSi. Fig. $2 \mathrm{c}(\mathrm{iv})$ shows the typical HRTEM image of $\mathrm{Ni}(\mathrm{OH})_{2}$ - $\mathrm{Si}$, in which the layered lattice structure with a fringe spacing of $0.45 \mathrm{~nm}$ can be observed clearly. The interplanar spacing corresponds to the $d$ spacing of the (001) plane of orthorhombic phase $\mathrm{Ni}(\mathrm{OH})_{2}$. Fig. 2c(v) represents the corresponding selected area electron diffraction (SAED) pattern of $\mathrm{Ni}(\mathrm{OH})_{2}$-Si. The obtained circular diffraction pattern with bright spots indicates that the obtained $\mathrm{Ni}(\mathrm{OH})_{2}$-Si possesses good crystallinity. For $\mathrm{NiSi} @ \mathrm{Ni}(\mathrm{OH})_{2}$, its surface is also covered with $\mathrm{Ni}(\mathrm{OH})_{2}$, which has the same SAED results as $\mathrm{Ni}(\mathrm{OH})_{2}-\mathrm{Si}$. For pure $\mathrm{NiSiO}_{x}$ (inset in Fig. S1i, ESI $\dagger$ ), the obscure circular shape in its SAED reveals its amorphous nature, which is different from that of $\mathrm{Ni}(\mathrm{OH})_{2}$-Si.
To obtain more information on $\mathrm{NiSi}-\mathrm{Ni}(\mathrm{OH})_{2}-4$, the EDS mapping spectra indicate that $\mathrm{NiSi}-\mathrm{Ni}(\mathrm{OH})_{2}-4$ is composed of $\mathrm{Si}, \mathrm{O}$ and Ni elements from both NiSi@Ni $(\mathrm{OH})_{2}$ and $\mathrm{Ni}(\mathrm{OH})_{2}-\mathrm{Si}$ [inset in Fig. 2d(i)]. By comparing the EDS spectra of NiSi@Ni(OH $)_{2}$ and $\mathrm{Ni}(\mathrm{OH})_{2}-\mathrm{Si}, \mathrm{Ni}(\mathrm{OH})_{2}-\mathrm{Si}$ contains a lower content of $\mathrm{Si}$, but higher content of $\mathrm{Ni}$ and $\mathrm{O}$. The separate EDS mapping spectra of NiSi@Ni(OH $)_{2}$ and $\mathrm{Ni}(\mathrm{OH})_{2}$-Si are shown in Fig. S3 and $\mathrm{S} 4(\mathrm{ESI} \dagger)$, respectively, which are in accordance with the results in Fig. 2 d. The element mapping tests indicate that the two morphologies contain different proportions of silicon. Hence, these results preliminary prove the successful formation of the $\mathrm{NiSi}-\mathrm{Ni}(\mathrm{OH})_{2}$ composite. To further prove the structural information of the NiSi-Ni(OH $)_{2}-4$ composite, XRD, IR and BET measurements were performed.

Fig. 3 shows the XRD patterns of the hydrothermally synthesized $\mathrm{NiSiO}_{x}, \mathrm{Ni}(\mathrm{OH})_{2}$ and $\mathrm{NiSi}-\mathrm{Ni}(\mathrm{OH})_{2}-4$. For the XRD pattern of $\mathrm{Ni}(\mathrm{OH})_{2}$ (Fig. 3a), the peaks at $2 \theta=19.6^{\circ}, 33.4^{\circ}, 38.8^{\circ}, 52.2^{\circ}$, $59.2^{\circ}, 62.7^{\circ}, 69.6^{\circ}, 70.8^{\circ}$ and $72.7^{\circ}$ can be attributed to the (001), (100), (101), (102), (110), (111), (200), (103) and (201) planes of $\mathrm{Ni}(\mathrm{OH})_{2}$, respectively (JCPDS No. 03-0177). The XRD pattern of nickel silicate in Fig. $3 \mathrm{~b}$ displays peaks at $2 \theta=11.9^{\circ}, 19.7^{\circ}, 24.3^{\circ}$, $36.7^{\circ}$ and $60.5^{\circ}$, which can be indexed to the (002), (110), (004), (200), (202) and (208) planes of $\mathrm{Ni}_{3} \mathrm{Si}_{2} \mathrm{O}_{5}(\mathrm{OH})_{4}$, respectively (JCPDS No. 22-0754). For the final samples $\mathrm{NiSi}-\mathrm{Ni}(\mathrm{OH})_{2}-1-5$ (Fig. S5, ESI $\dagger$ ), all the diffractions are a combination from $\mathrm{Ni}(\mathrm{OH})_{2}$ and $\mathrm{NiSiO}_{x}$. As a comparison, the XRD pattern of the $\mathrm{SiO}_{2}$ obtained via the Stöber method is shown in Fig. S5 (ESI $\dagger$ ), which shows a broad peak, exhibiting an amorphous state. When the amount of nickel species increased, nickel silicate was generated initially, as can be seen from the XRD pattern of $\mathrm{NiSi}-\mathrm{Ni}(\mathrm{OH})_{2}-1$

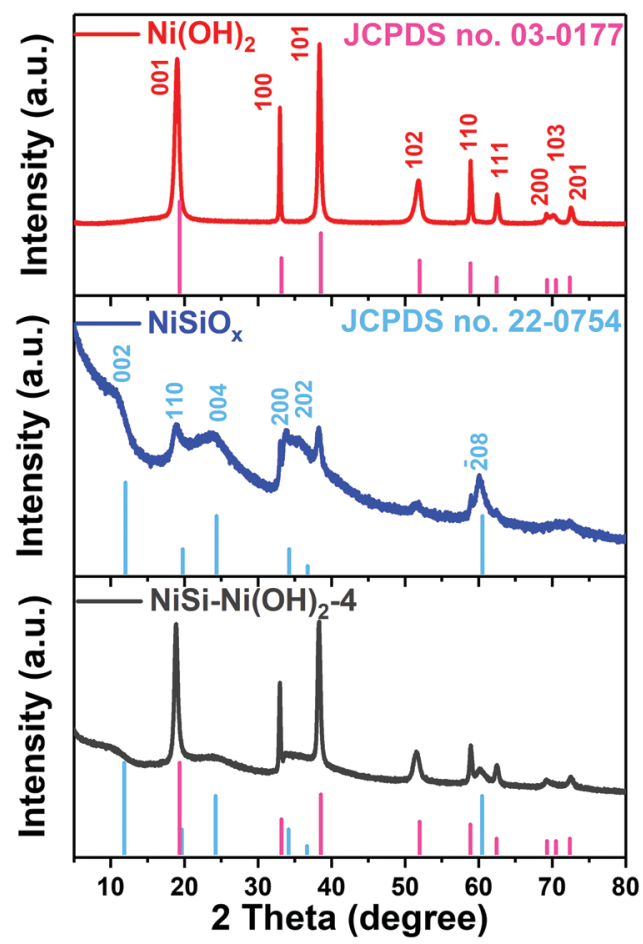

Fig. 3 XRD patterns of $\mathrm{Ni}(\mathrm{OH})_{2}, \mathrm{NiSiO}_{x}$ and $\mathrm{NiSi}-\mathrm{Ni}(\mathrm{OH})_{2}-4$. 
in Fig. S5 (ESI $\dagger$ ). Subsequently, besides the peak at $60.5^{\circ}$, the peaks of $\mathrm{NiSiO}_{x}$ became relatively weak compared with that of $\mathrm{Ni}(\mathrm{OH})_{2}$, which is due to the elevated amount of nickel species. Thus, the XRD results prove that the $\mathrm{NiSi}-\mathrm{Ni}(\mathrm{OH})_{2}-n$ composites were successfully synthesized.

To compare the specific structures of $\mathrm{Ni}(\mathrm{OH})_{2}, \mathrm{NiSiO}_{x}$ and $\mathrm{NiSi}-\mathrm{Ni}(\mathrm{OH})_{2}$, FT-IR spectroscopy was performed, as shown in Fig. S6 (ESI $\dagger)$. For $\mathrm{Ni}(\mathrm{OH})_{2}$, the peak at $520 \mathrm{~cm}^{-1}$ is ascribed to the in-plane deformation vibration of $\mathrm{O}-\mathrm{H}$. The small peaks at 1380-1390 and $1480-1490 \mathrm{~cm}^{-1}$ are attributed to the $\mathrm{O}-\mathrm{H}$ bending modes of the lattice $\mathrm{OH}$. The narrow peak at $\sim 3427 \mathrm{~cm}^{-1}$ is assigned to the $\mathrm{O}-\mathrm{H}$ vibration of the hydrogenbonded hydroxyl groups. ${ }^{25}$ The FT-IR results for $\mathrm{Ni}(\mathrm{OH})_{2}$ indicate that it contains a rich content of hydroxyls. For $\mathrm{NiSiO}_{x}$, the peaks at $\sim 801 \mathrm{~cm}^{-1}$ and $\sim 464 \mathrm{~cm}^{-1}$ are attributed to the symmetrical stretching vibrations of the $\mathrm{Si}-\mathrm{O}-\mathrm{Si}$ structure and symmetrical stretching vibration of $\mathrm{Si}-\mathrm{O}$, respectively. ${ }^{49,50}$ The peak located at $670 \mathrm{~cm}^{-1}$ is assigned to the lattice vibration of $\mathrm{Ni}-\mathrm{O}$ in nickel silicate. ${ }^{51}$ The peak located at $1106 \mathrm{~cm}^{-1}$ is attributed to the formation of Si-O-Ni bonds. The narrow peak at $3672 \mathrm{~cm}^{-1}$ corresponds to the stretching mode of the hydroxyl $(-\mathrm{OH})$ in $\mathrm{Ni}_{3} \mathrm{Si}_{2} \mathrm{O}_{5}(\mathrm{OH})_{4} \cdot{ }^{52,53}$ For NiSi-Ni $(\mathrm{OH})_{2}-4$, the peaks at $670 \mathrm{~cm}^{-1}$ and $1008 \mathrm{~cm}^{-1}$ are assigned to the tetrahedral $\mathrm{SiO}$ mode and Si-O stretching, respectively. ${ }^{54}$ The peak at $3667 \mathrm{~cm}^{-1}$ is associated with the clusters of $\mathrm{Si}-\mathrm{OH}$ groups in a small dimension. The peak at $3640 \mathrm{~cm}^{-1}$ is attributed to the $\nu_{\mathrm{OH}}$ vibration related to the nickel hydroxide and/or the octahedral-coordinated Ni(II) in the brucite-type sheet of $1: 1$ nickel phyllosilicate. ${ }^{55}$ To further clarify the difference between $\mathrm{NiSi}-\mathrm{Ni}(\mathrm{OH})_{2}-n$ and a mixture of $\mathrm{Ni}(\mathrm{OH})_{2}$ and $\mathrm{NiSiO}_{x}$, we also compared their FT-IR spectra (not shown). The result also indicates that NiSi-Ni(OH $)_{2}-4$ is not a mixture of $\mathrm{NiSiO}_{x}$ and $\mathrm{Ni}(\mathrm{OH})_{2}$.

The nitrogen adsorption-desorption isotherms of the products were measured to observe their specific surface and pore size distribution. As shown in Fig. 4, all the isotherms can be categorized as type IV, which is the typical characteristic of mesopores. The Brunauer-Emmett-Teller (BET) specific surface areas of $\mathrm{NiSiO}_{x}, \mathrm{Ni}(\mathrm{OH})_{2}$ and $\mathrm{NiSi}-\mathrm{Ni}(\mathrm{OH})_{2}-4$ are 327.3, 27.7 and $239.4 \mathrm{~m}^{2} \mathrm{~g}^{-1}$, respectively. The combination of two morphologies indicates that the self-assembly of thin nanosheets results in a high specific surface area. By using the Barrett-Joyner-Halenda (BJH) method, the pore size distributions were calculated via the desorption branch of the isotherms. In Fig. 4, the pore sizes of $\mathrm{NiSiO}_{x}, \mathrm{Ni}(\mathrm{OH})_{2}$ and $\mathrm{NiSi}-\mathrm{Ni}(\mathrm{OH})_{2}-4$ are 5.6, 34.9 and $5.5 \mathrm{~nm}$, and their $\mathrm{BJH}$ desorption cumulative pore volumes are $0.57,0.18$ and $0.35 \mathrm{~cm}^{3} \mathrm{~g}^{-1}$, respectively. Considering its specific surface, pore size distribution and pore volume, $\mathrm{NiSi}-\mathrm{Ni}(\mathrm{OH})_{2}-4$ may be an ideal candidate for use in supercapacitors.

XPS analysis was carried out to further prove the successful formation and investigate the surface elemental information of $\mathrm{NiSi}-\mathrm{Ni}(\mathrm{OH})_{2}-4$. From the spectra in Fig. $5 \mathrm{a}$, it can observed that the product is composed of $\mathrm{Si}, \mathrm{O}$ and Ni elements. As shown in Fig. 5b, the binding energies at $874.1 \mathrm{eV}$ and $856.5 \mathrm{eV}$ correspond to $\mathrm{Ni} 2 \mathrm{p}_{3 / 2}$ and $\mathrm{Ni} 2 \mathrm{p}_{1 / 2}$, respectively, indicating the presence of $\mathrm{Ni}$ (II) species. The binding energies at $880.1 \mathrm{eV}$ and $862.4 \mathrm{eV}$ are shakeup satellite peaks of Ni element, also proving the presence of $\mathrm{Ni}(\mathrm{II})$ species. ${ }^{56}$ The high-resolution $\mathrm{O}$ 1s spectrum in Fig. 5c demonstrates the presence of $\mathrm{H}-\mathrm{O}-\mathrm{H}$ (532.6 eV), Ni-O (531.9 eV) and Si-O (530.9 eV) in NiSi-Ni(OH $)_{2}-4$. Besides, the $\mathrm{Si} 2 \mathrm{p}$ core-level spectrum in Fig. $5 \mathrm{~d}$ presents the binding energy located at $\sim 103.2 \mathrm{eV}$, and this value is larger than the previously reported $102.5 \mathrm{eV}$ as a characteristic value for nickel silicate hydroxides, revealing the unique structure of $\mathrm{NiSi}-\mathrm{Ni}(\mathrm{OH})_{2}-4 .^{57}$ Thus, these results reveal the successful formation and unique structure of $\mathrm{NiSi}-\mathrm{Ni}(\mathrm{OH})_{2}-4$.

The energy storage performance of the products was evaluated by cyclic voltammetry (CV), galvanostatic charge/discharge (GCD) and electrochemical impedance spectroscopy (EIS) tests in $3 \mathrm{M}$ $\mathrm{KOH}$ aqueous solution. For comparison, the results of pure $\mathrm{Ni}(\mathrm{OH})_{2}$ and $\mathrm{NiSiO}_{x}$ are also presented. Fig. 6a shows the comparative voltage window selection of the $\mathrm{NiSi}-\mathrm{Ni}(\mathrm{OH})_{2}$ sample. By varying the voltage window in the range of -0.1 to $0.8 \mathrm{~V}$, the proper voltage of $\mathrm{NiSi}-\mathrm{Ni}(\mathrm{OH})_{2}$ was determined to be 0.1-0.6 V. Fig. 6b shows the comparative CV curves of $\mathrm{Ni}(\mathrm{OH})_{2}$, $\mathrm{NiSiO}_{x}$ and $\mathrm{NiSi}-\mathrm{Ni}(\mathrm{OH})_{2}-1-5$ at scanning rates of $5,10,20,50$ and $100 \mathrm{mV} \mathrm{s}^{-1}$. NiSi-Ni(OH $)_{2}-1$ and $\mathrm{NiSiO}_{x}$ showed very low charge storage capability, and the capacitance is increased with
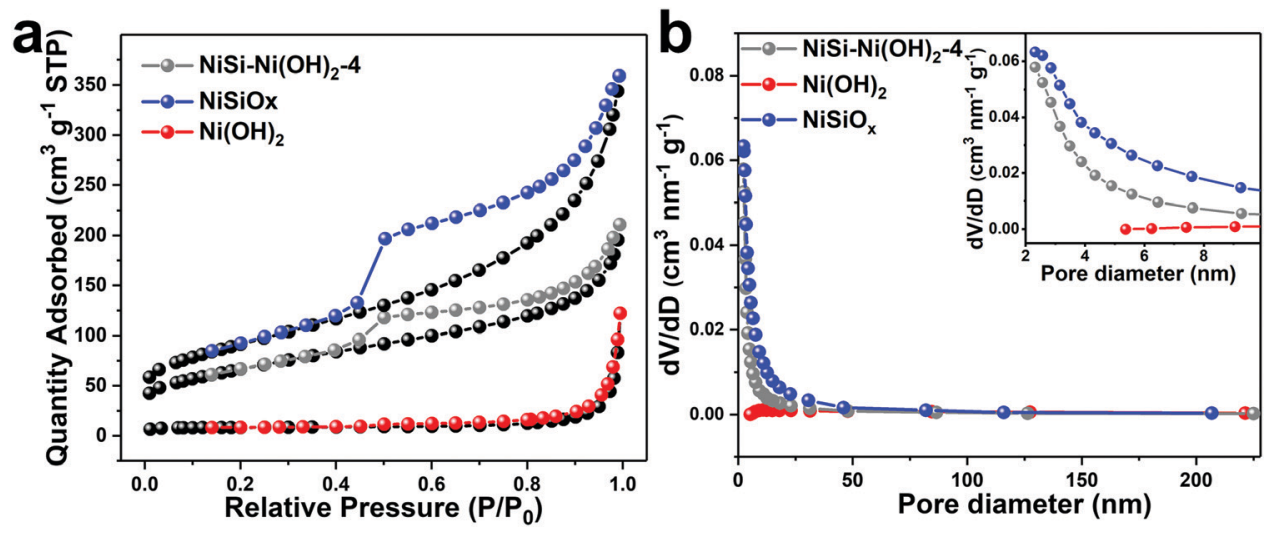

Fig. 4 (a) Nitrogen adsorption and desorption isotherms of $\mathrm{Ni}(\mathrm{OH})_{2}, \mathrm{NiSiO}_{x}$ and $\mathrm{NiSi}-\mathrm{Ni}(\mathrm{OH})_{2}-4$. (b) Pore size distribution plots of $\mathrm{Ni}(\mathrm{OH})_{2}, \mathrm{NiSiO} \mathrm{O}_{x}$ and $\mathrm{NiSi}-\mathrm{Ni}(\mathrm{OH})_{2}-4$. 

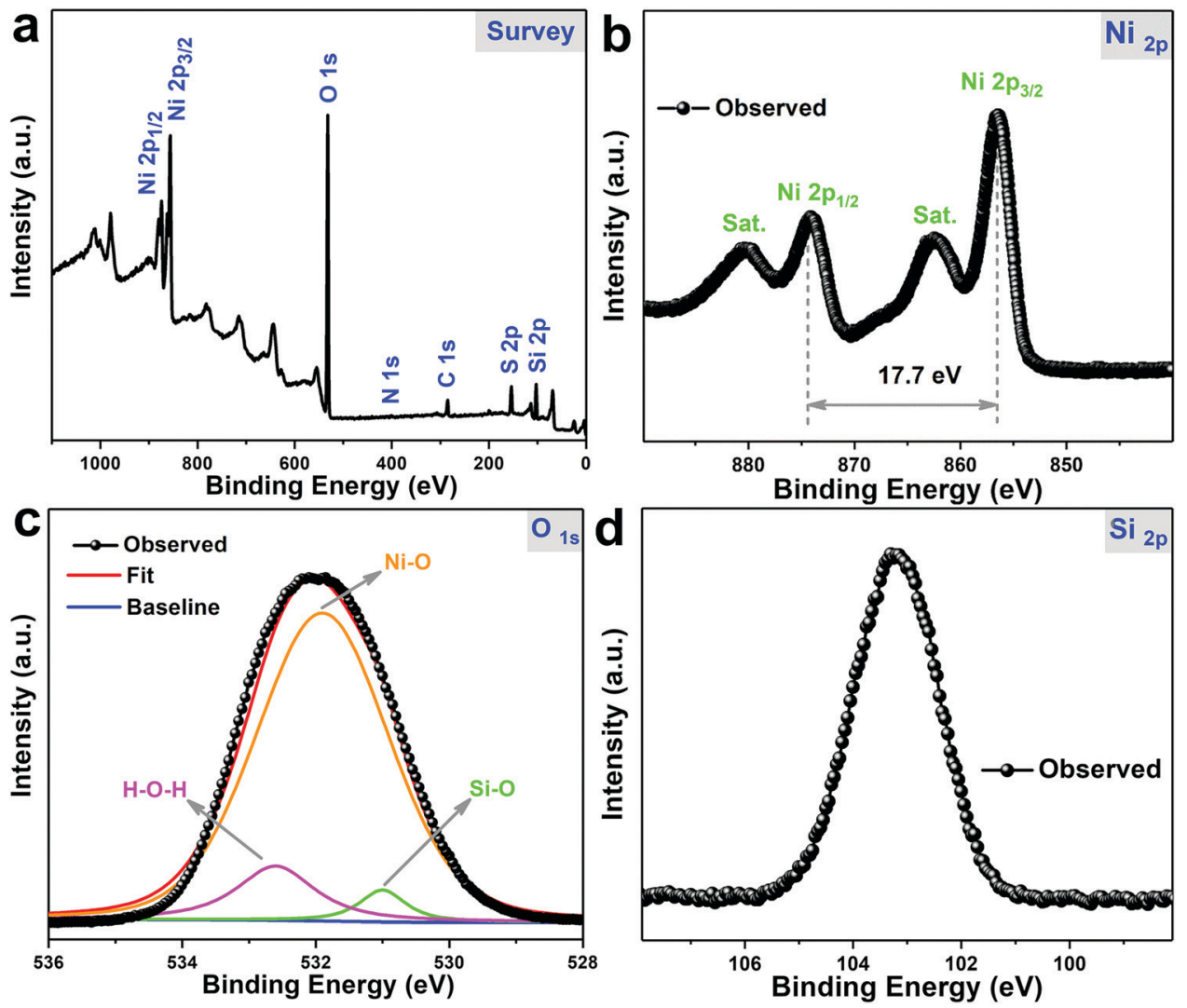

Fig. 5 XPS spectra of $\mathrm{NiSi}-\mathrm{Ni}(\mathrm{OH})_{2}-4$ : (a) full spectrum, (b) $\mathrm{Ni} 2 \mathrm{p}$, (c) $\mathrm{O}$ 1s and (d) $\mathrm{Si} 2 \mathrm{p}$.

an increase in the amount of nickel species. In the CV curves, the pair of large redox peaks correspond to the reversible redox reaction of $\mathrm{Ni}(\mathrm{II})$ to $\mathrm{Ni}(\mathrm{III})$. This reaction can be clarified as follows:

$$
\begin{gathered}
\mathrm{Ni}(\mathrm{OH})_{2}+\mathrm{OH}^{-} \leftrightarrow \mathrm{NiOOH}+\mathrm{H}_{2} \mathrm{O}+\mathrm{e}^{-} \\
\mathrm{Ni}_{3}^{\mathrm{II}} \mathrm{Si}_{2} \mathrm{O}_{5}(\mathrm{OH})_{4}+3 \mathrm{OH}^{-} \leftrightarrow \mathrm{Ni}_{3}^{\mathrm{III}} \mathrm{Si}_{2} \mathrm{O}_{5}(\mathrm{OH})_{5}+3 \mathrm{e}^{-}
\end{gathered}
$$

The above results reveal the intercalation and deintercalation of protons, ${ }^{58}$ which suggest that the electrochemical mechanism of $\mathrm{NiSi}-\mathrm{Ni}(\mathrm{OH})_{2}$ is battery-like capacitance originating from the faradaic processes on the $\mathrm{NiSi}-\mathrm{Ni}(\mathrm{OH})_{2}$ nanoplates. Besides, compared to the asymmetric characteristics of $\mathrm{Ni}(\mathrm{OH})_{2}, \mathrm{NiSi}-\mathrm{Ni}(\mathrm{OH})_{2}$ and $\mathrm{NiSiO}_{x}$ showed highly symmetric characteristics of anodic and cathodic peaks, indicating their high redox reversibility (Fig. S7, $\mathrm{ESI} \dagger$ ). It is well known that the capacity of electrode materials consists of two components, and it is necessary to determine the diffusion-controlled capacity and capacitive capacity to determine the battery-like capacitive contribution from the electrodes during the electrochemical reaction. The relationship between the diffusion-controlled capacity and capacitive capacity is summarized by eqn (17) as follows: ${ }^{59}$

$$
I(V)=k_{1} \nu+k_{1} \nu^{1 / 2}
$$

where, $k_{1}$ represents the capacitive contribution and $k_{2}$ represents the diffusion-controlled contribution for the total capacity at a specific voltage and $\nu$ represents the sweep rate.
Fig. S7 (ESI $\dagger$ ) shows all the CV curves at different scan rates ranging from 5 to $100 \mathrm{mV} \mathrm{s}^{-1}$ for the three electrodes. The specific capacitive contribution from the CV curves of the electrodes gradually increased with an increase in scan rate, indicative of the dominant capacitive contribution at a high rate, as illustrated in Fig. S7h (ESI $\dagger$ ). In Fig. 7h, according to the obvious CV curve of a capacitive current (pink region) compared to the total current (blue region), it can also be concluded that the $\mathrm{NiSi}-\mathrm{Ni}(\mathrm{OH})_{2}-n$ composite exhibits a remarkable rate performance due to its capacitive contribution from its hollow spherical morphology and the combination of $\mathrm{NiSi}$ and $\mathrm{Ni}(\mathrm{OH})_{2}$. According to the overall data in Fig. S7i $(\mathrm{ESI} \dagger), \mathrm{NiSi}-\mathrm{Ni}(\mathrm{OH})_{2}-1$ possesses the highest capacitive capacity (increasing from $60.4 \%$ to $96.4 \%$ ), and $\mathrm{NiSi}-\mathrm{Ni}(\mathrm{OH})_{2}-5$ owned the lowest capacitive capacity (increasing from $10.4 \%$ to $69.5 \%$ ). Previous researchers have reported that electrode materials with high battery-like capacitance tend to display low-diffusion-controlled capacity, whereas the opposite is observed for low battery-like capacitance electrode materials. ${ }^{60}$ Hence, it is better to increase the diffusion-controlled capacity of high battery-like capacitance electrodes and the capacitive contribution of low battery-like capacitance electrodes. Specifically, in Fig. S7i (ESI $\dagger$ ), the diffusion contribution of $\mathrm{NiSi}-\mathrm{Ni}(\mathrm{OH})_{2}-1-5$ maintained an upward trend, and the capacitive capacity contribution exhibited a downward trend. This simply suggests that the combination of $\mathrm{NiSi}$ and $\mathrm{Ni}(\mathrm{OH})_{2}$ is an effective method for elevating both the diffusion and capacitive 

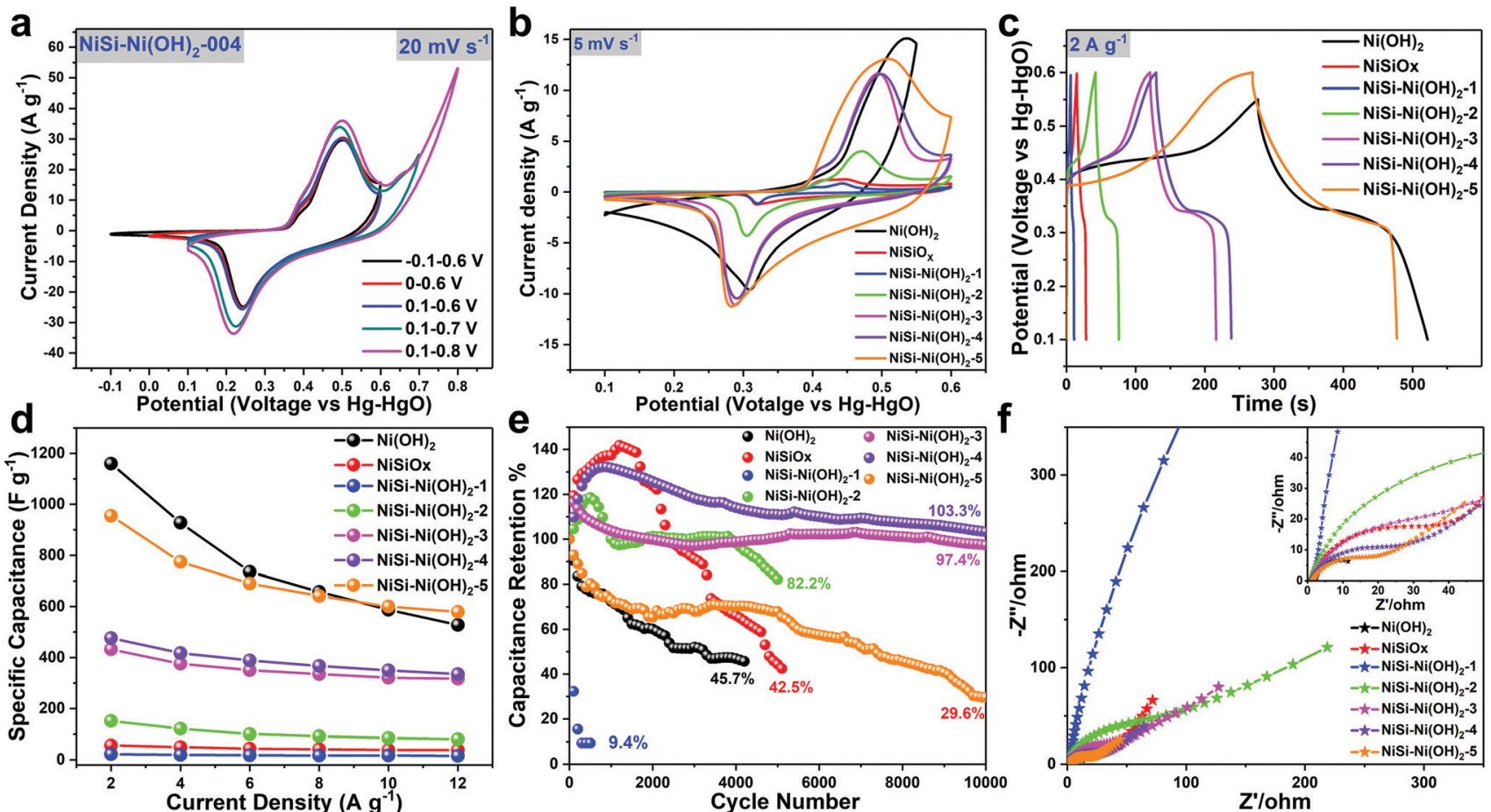

Fig. 6 (a) Voltage window selection of $\mathrm{NiSi}-\mathrm{Ni}(\mathrm{OH})_{2}-4$ at a scan rate of $5 \mathrm{mV} \mathrm{s}^{-1}$. (b) Comparison of the $\mathrm{CV}$ profiles at a scan rate of $5 \mathrm{mV} \mathrm{s} \mathrm{s}^{-1}$. (c) Comparison of the GCD profiles measured at a current density of $2 \mathrm{~A} \mathrm{~g}^{-1}$. (d) Specific capacitances of the products obtained from the GCD curves at various current densities $\left(2,4,6,8,10\right.$ and $12 \mathrm{~A} \mathrm{~g}^{-1}$ ). (e) Cycle performance of the products obtained from the CV curves at $20 \mathrm{mV} \mathrm{s}^{-1}$. (f) Nyquist plots of the products. The insets are the enlarged Nyquist plots from the high-frequency region.

contributions of electrode materials. The galvanostatic charge/ discharge curves of $\mathrm{Ni}(\mathrm{OH})_{2}, \mathrm{NiSiO}_{x}$ and $\mathrm{NiSi}-\mathrm{Ni}(\mathrm{OH})_{2}$ at different charge/discharge current densities are shown in Fig. 6c and Fig. S8 (ESI $\dagger$ ). All the curves in Fig. 6c present typical battery-like behavior, in accordance with their $\mathrm{CV}$ curves. The specific capacitances of $\mathrm{NiSiO}_{x}, \mathrm{Ni}(\mathrm{OH})_{2}$ and $\mathrm{NiSi}-\mathrm{Ni}(\mathrm{OH})_{2}-1-5$ are $56.4,1159.3,22.0,151.8,432.4,476.4$ and $954.8 \mathrm{~F} \mathrm{~g}^{-1}$ at a current density of $2 \mathrm{~A} \mathrm{~g}^{-1}$. In Fig. $6 \mathrm{~d}$, the rate performance of $\mathrm{Ni}(\mathrm{OH})_{2}, \mathrm{NiSiO}_{x}$ and $\mathrm{NiSi}-\mathrm{Ni}(\mathrm{OH})_{2}-1-5$ is $45.5 \%, 68.0 \%, 70.9 \%, 52.9 \%, 73.3 \%, 70.3 \%$ and $60.7 \%$, respectively. By comparing their specific capacitances at current densities ranging from $2 \mathrm{~A} \mathrm{~g}^{-1}$ to $12 \mathrm{~A} \mathrm{~g}^{-1}$, it was found that the capacitance of the products was elevated with an increase in the amount of nickel species and performed the best at on optimum ratio of $\mathrm{Ni} / \mathrm{Si}$. Besides, a visibly lower capacitance loss of $29.7 \%$ for $\mathrm{NiSi}-\mathrm{Ni}(\mathrm{OH})_{2}-4$ at a high charge/discharge current density of $12 \mathrm{~A} \mathrm{~g}^{-1}$ was also observed, in contrast to $54.4 \%$ for $\mathrm{Ni}(\mathrm{OH})_{2}$ at $12 \mathrm{~A} \mathrm{~g}^{-1}$. This result indicates that the NiSi-Ni(OH $)_{2}-4$ electrode can provide a more reliable capacitive performance at higher current densities when applied as a high power device. Fig. 6e demonstrates the cycling performance of $\mathrm{Ni}(\mathrm{OH})_{2}, \mathrm{NiSiO}_{x}$ and $\mathrm{NiSi}-\mathrm{Ni}(\mathrm{OH})_{2}-1-5$ at $20 \mathrm{mV} \mathrm{s}^{-1}$. After the completion of various cycles, the $\mathrm{Ni}(\mathrm{OH})_{2}, \mathrm{NiSiO}_{x}$ and $\mathrm{NiSi}-\mathrm{Ni}(\mathrm{OH})_{2}-1-5$ electrode materials maintained $45.7 \%, 42.5 \%, 9.4 \%, 82.2 \%, 97.4 \%$, $103.3 \%$ and $29.6 \%$, respectively, of their initial performance. The cycle stability of NiSi-Ni(OH$)_{2}-4$ was the best, which also indicates its optimum ratio of $\mathrm{Ni} / \mathrm{Si}$. When compared to previously reported nickel silicate/nickel hydroxide-based materials, its cycle stability is superior to most of the materials (Table S1, ESI†). The excellent rate capability and excellent cycling stability of $\mathrm{NiSi}-\mathrm{Ni}(\mathrm{OH})_{2}-4$ can be attributed to the synergistic effect originating from the extreme nanohybridization. Firstly, the thin lamellar structure of both $\mathrm{NiSi}$ and $\mathrm{Ni}(\mathrm{OH})_{2}$ not only facilitate the penetration of electrolyte into the material, but also significantly shorten the diffusion distance, resulting in an improved the superior rate performance. Secondly, the porous spherical structures of both NiSi and $\mathrm{Ni}(\mathrm{OH})_{2}$ can accommodate the volume variation during the faradaic reaction in longterm cycles. More significantly, the hybridized $\mathrm{NiSi}-\mathrm{Ni}(\mathrm{OH})_{2}$ possess the advantages of both $\mathrm{NiSi}$ and $\mathrm{Ni}(\mathrm{OH})_{2}$, which maximize the utilization of individual components and stabilize the structure of the electrode material. Fig. 6f displays the Nyquist plot of $\mathrm{Ni}(\mathrm{OH})_{2}, \mathrm{NiSiO}_{x}$ and $\mathrm{NiSi}-\mathrm{Ni}(\mathrm{OH})_{2}-1-5$ with the frequency ranging from 0.01 to $100000 \mathrm{~Hz}$. From the electrochemical impedance spectroscopy (EIS) results, it can be observed that the individual contact resistance of $\mathrm{Ni}(\mathrm{OH})_{2}$, $\mathrm{NiSiO}_{x}$ and $\mathrm{NiSi}-\mathrm{Ni}(\mathrm{OH})_{2}-1-5$ is $0.9,1.8,1.3,1.1,1.5,1.3$ and $1.6 \mathrm{Ohm}$, respectively. The small contact resistance may be attributed to the hollow spherical structure. In previous reports, due to the poor rate capability of $\mathrm{Ni}(\mathrm{OH})_{2}$, it is usually converted into $\mathrm{NiO}_{x}$, together with a decrease in capacitance. ${ }^{61-63}$ Herein, this transformation was also observed. Fig. S9 (ESI $\dagger$ ) presents the XRD patterns and SEM images of the products after the cycling test. In the XRD pattern of $\mathrm{NiSi}-\mathrm{Ni}(\mathrm{OH})_{2}-4$ after cycling (Fig. S9a, ESI $\dagger$ ), besides the peaks of $\mathrm{Ni}(\mathrm{OH})_{2}$ (JCPDS No. 03-0177) and $\mathrm{Ni}_{3} \mathrm{Si}_{2} \mathrm{O}_{5}(\mathrm{OH})_{4}$ (JCPDS No. 22-0754), new peaks appeared at 

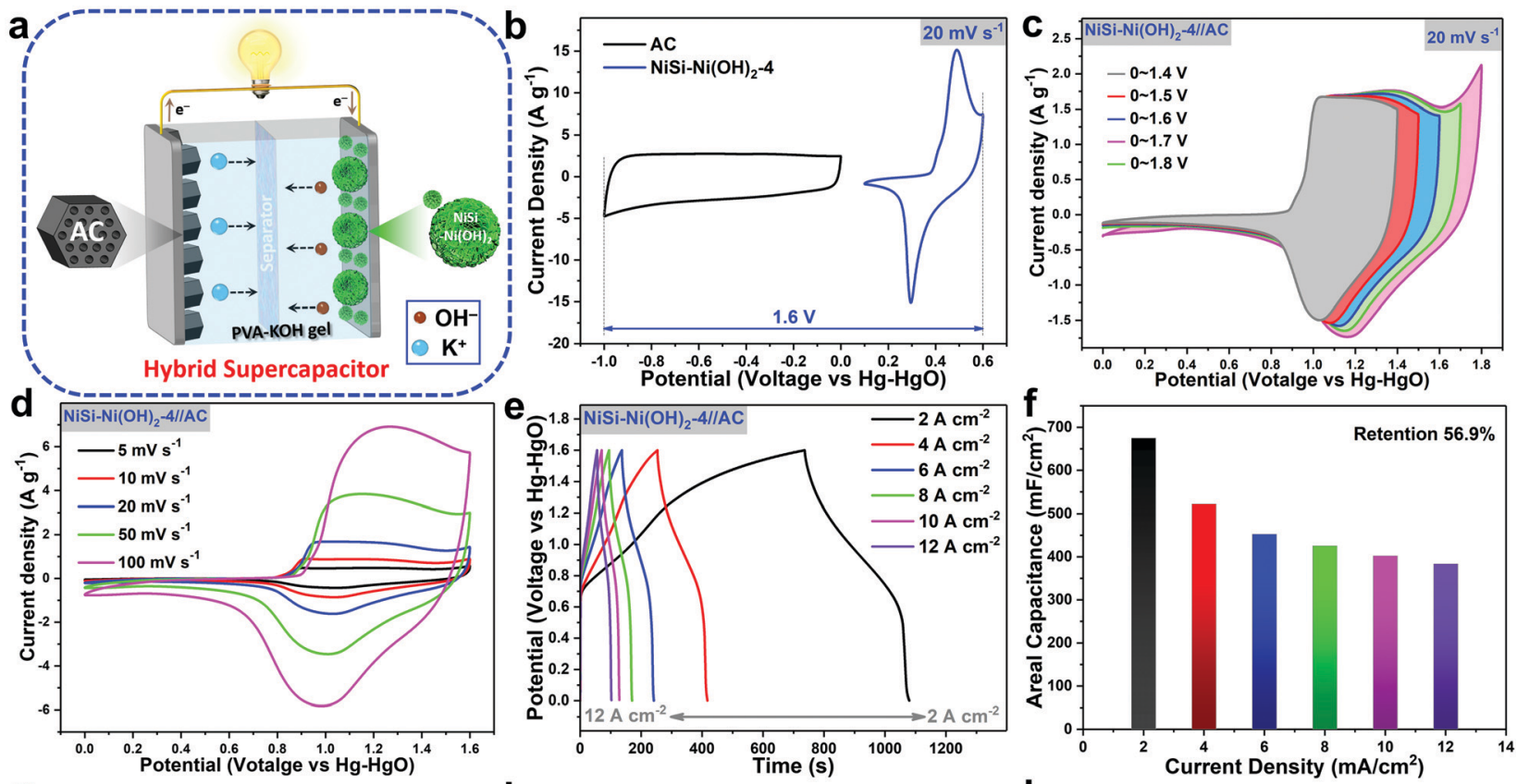

g

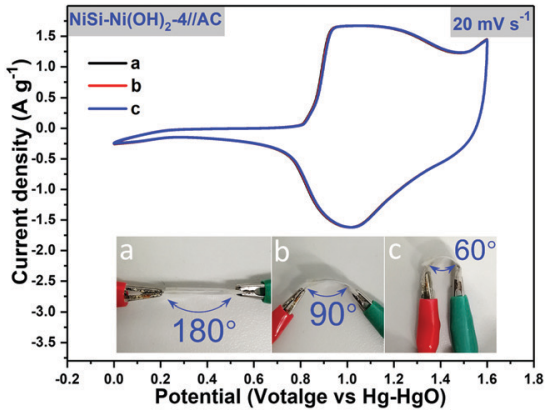

h

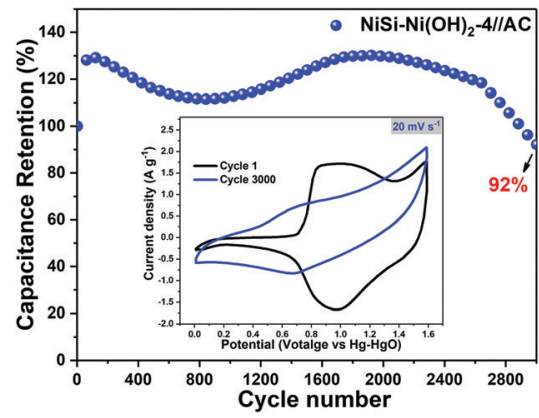

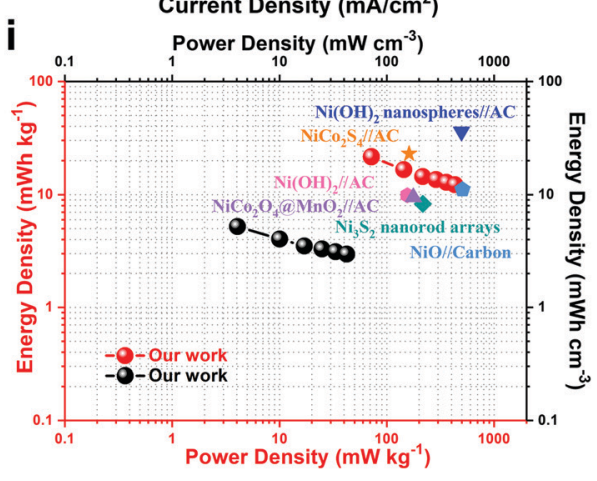

Fig. 7 (a) Schematic illustration of the assembled $\mathrm{HSC}$ with $\mathrm{NiSi}-\mathrm{Ni}(\mathrm{OH})_{2}-4$ and $\mathrm{AC}$ as the positive and negative electrodes, respectively. (b) CV curves of individual $\mathrm{NiSi}-\mathrm{Ni}(\mathrm{OH})_{2}-4$ and $\mathrm{AC}$. (c) Voltage window selection of $\mathrm{NiSi}-\mathrm{Ni}(\mathrm{OH})_{2}-4 / / \mathrm{AC}$ at a scan rate of $20 \mathrm{mV} \mathrm{s}^{-1}$. (d) $\mathrm{CV}$ and (e) GCD curves of the HSC devices at different scan rates and current densities. (f) Specific capacitances of the HSC devices obtained from the GCD curves at various current densities $\left(2,4,6,8,10\right.$ and $12 \mathrm{~mA} \mathrm{~cm}^{-2}$ ). (g) CV curves of the HSC devices at different bending angles at a scan rate of $20 \mathrm{mV} \mathrm{s}^{-1}$. (h) Cycle performance of HSC devices obtained from the CV curves at $20 \mathrm{mV} \mathrm{s}^{-1}$. (i) Ragone plot (power density to energy density) of the HSC devices.

$39.0^{\circ}, 44.6^{\circ}$ and $60.5^{\circ}$, which can be attributed to $4 \mathrm{Ni}(\mathrm{OH})_{2}-$ $\mathrm{NiOOH}$ (JCPDS No. 22-0754), and at $28.5^{\circ}, 29.7^{\circ}, 30.8^{\circ}, 38.0^{\circ}$, $49.7^{\circ}$ and $50.5^{\circ}$, assigned to $\mathrm{Ni}(\mathrm{CO})_{4}$ (JCPDS No. 22-0754). In the XRD results, no obvious peaks attributed to $\mathrm{NiSiO}_{x}$ were found, and we suppose that $\mathrm{NiSiO}_{x}$ was sacrificed to protect the $\mathrm{Ni}(\mathrm{OH})_{2}$ and prolong the cycle performance. The conversion between $\mathrm{Ni}(\mathrm{OH})_{2}, 4 \mathrm{Ni}(\mathrm{OH})_{2}-\mathrm{NiOOH}$ and $\mathrm{Ni}(\mathrm{CO})_{4}$ explains the unsymmetrical redox peaks of the respective $\mathrm{NiSi}-\mathrm{Ni}(\mathrm{OH})_{2}$ configurations, revealing the irreversibility of the redox processes. The conversion between $\mathrm{Ni}(\mathrm{OH})_{2}$ and $4 \mathrm{Ni}(\mathrm{OH})_{2}-\mathrm{NiOOH}$ is common for battery-like supercapacitor materials during the redox reaction, where the electrolyte diffuses in the porous electrode and the ions are charged and discharged continuously, leading to ohmic resistance and polarization. In addition, we also discovered that $\mathrm{Ni}(\mathrm{OH})_{2}$ was converted to $\mathrm{Ni}(\mathrm{CO})_{4}$ during the electrochemical reaction. This reaction can be clarified as:

$$
2 \mathrm{C}+\mathrm{O}_{2} \leftrightarrow 2 \mathrm{CO}
$$

$$
\mathrm{Ni}(\mathrm{OH})_{2}+4 \mathrm{CO}+2 \mathrm{e}^{-} \leftrightarrow \mathrm{Ni}(\mathrm{CO})_{4}+2 \mathrm{OH}^{-}
$$

which shows that the CO molecules are formed by acetylene black reacting with the soluble oxygen in the electrolyte, then $\mathrm{Ni}(\mathrm{CO})_{4}$ is generated by the reaction between $\mathrm{Ni}(\mathrm{OH})_{2}$ and $\mathrm{CO}$. This result illustrates that the usage of acetylene black can improve the conductivity of the electrode material in the electrochemical reaction, but it may be simultaneously harmful to the cycling performance of nickel-based materials. The formation of $\mathrm{Ni}(\mathrm{CO})_{4}$ will further decrease the cycle performance. The SEM images in Fig. S9b-e (ESI $\dagger$ ) further identify this phenomenon, where after cycling, $\mathrm{NiSi}-\mathrm{Ni}(\mathrm{OH})_{2}$ showed a curved platelet morphology compared to the original morphology, indicating that the ion-insertion affects the morphology. Besides, most of the $\mathrm{Ni}(\mathrm{OH})_{2}$-Si was maintained without obvious $\mathrm{NiSiO}_{x}$ found, which is also proof of our hypothesis. TEM was also performed to support this hypothesis, and in Fig. S9f-i $(\mathrm{ESI} \dagger)$, a random dispersion of nanoflakes of $\mathrm{Ni}(\mathrm{OH})_{2}$-Si can be 
observed after cycling. The $\mathrm{Ni}(\mathrm{OH})_{2}$-Si nanoflakes were partially merged with the acetylene black nanoparticles. From the enlarged image of the $\mathrm{Ni}(\mathrm{OH})_{2}$-Si nanoflakes, a well-preserved fragment of $\mathrm{Ni}(\mathrm{OH})_{2}$-Si is presented and a clear crystal lattice can be observed. Similarly, there was no evidence of $\mathrm{NiSiO}_{x}$ found in $\mathrm{Ni}(\mathrm{OH})_{2}-\mathrm{Si}$ after cycling, in accordance with the SEM results.

To further illustrate the practical application of the as-prepared products, a hybrid asymmetrical supercapacitor (HSC) composed of $\mathrm{NiSi}-\mathrm{Ni}(\mathrm{OH})_{2}-4$ as the positive electrode and porous activated carbon (AC) as the negative electrode in PVA-KOH gel electrolyte was fabricated (as shown in Fig. 7a). To explore the specific voltage window of the $\mathrm{HSC}$, the individual $\mathrm{CV}$ curves of $\mathrm{NiSi}-\mathrm{Ni}(\mathrm{OH})_{2}-4$ and $\mathrm{AC}$ are shown in Fig. 7b. Fig. 7c shows the typical $\mathrm{CV}$ curves of the HSC at various voltage windows between 1.4 and $1.8 \mathrm{~V}$. As the voltage window increased, a gradually elevated area was presented, in accordance with the increase in specific capacitance. However, when the voltage window was higher than $1.6 \mathrm{~V}$, it was observed that the aqueous electrolyte decomposed with hydrogen or oxygen evolution. Fig. 7d presents the $\mathrm{CV}$ curves at various scan speeds ranging from $5 \mathrm{mV} \mathrm{s}^{-1}$ to $100 \mathrm{mV} \mathrm{s}^{-1}$, which show two strong redox peaks in each curve, originating from the battery-like activities induced by faradaic reactions. Fig. 7e presents the GCD curves at various current densities in the range of $2 \mathrm{~mA} \mathrm{~cm} \mathrm{~cm}^{-2}$ to $20 \mathrm{~mA} \mathrm{~cm} \mathrm{~cm}^{-2}$. The nonlinear GCD curves between 0 and $1.6 \mathrm{~V}$ further indicate a faradaic reaction occurred in the device. Taking advantage of the synergistic effect of $\mathrm{Ni}(\mathrm{OH})_{2}$ and $\mathrm{NiSi}$, the HSC delivered a maximum areal capacitance of 674.7, 521.9, 452.6, 425.5, 420.2, and $383.6 \mathrm{mF} \mathrm{cm}^{-2}$ at the current densities of 2, 4, 6, 8, 10, 12 and $20 \mathrm{~mA} \mathrm{~cm}^{-2}$, respectively (Fig. 7f). As shown in Fig. 7f, even at a very high areal capacitance of $20 \mathrm{~mA} \mathrm{~cm}{ }^{-2}$, the device showed a specific capacitance of $383.6 \mathrm{mF} \mathrm{cm}^{-2}$, corresponding to a capacitance retention of $56.9 \%$. To evaluate the influence of the bending angle on the specific performance, the HSC device was tested using the CV method at a scanning speed of $20 \mathrm{mV} \mathrm{s}^{-1}$ (Fig. 7g). The CV curves of the capacitor barely changed at $60^{\circ}, 90^{\circ}$ and $180^{\circ}$, demonstrating its flexibility. Cycling performance is another crucial factor to evaluate the capacitor. The assembled asymmetric supercapacitor with $\mathrm{NiSi}-\mathrm{Ni}(\mathrm{OH})_{2}-4 / / \mathrm{AC}$ as the electrodes in $\mathrm{KOH}-\mathrm{PVA}$ electrolyte gel was charged-discharged for 3000 cycles at a current density of $2 \mathrm{~mA} \mathrm{~cm}^{-2}$ (Fig. 7h). The capacitor demonstrated a high retention rate of $92 \%$ after 3000 cycles, which reveals its excellent cycling durability. The Ragone plots display a connection between the specific energy density and power density of the capacitor. In Fig. 7i, the specific maximum energy density the HSC device was $21.6 \mathrm{~W} \mathrm{~h} \mathrm{~kg} \mathrm{~g}^{-1}$ $\left(5.2 \mathrm{~mW} \mathrm{~h} \mathrm{~cm}{ }^{-3}\right)$ when the power density was $431.7 \mathrm{~W} \mathrm{~kg}^{-1}$ $\left(104.3 \mathrm{~mW} \mathrm{~cm}^{-3}\right)$, which is equal to or higher than that of most of the previously reported nickel hydroxide/nickel silicate-based asymmetric supercapacitors in aqueous electrolytes, such as $\mathrm{Ni}(\mathrm{OH})_{2}$ nanospheres//AC (35.7 $\left.\mathrm{W} \mathrm{h} \mathrm{kg}^{-1}, 490 \mathrm{~W} \mathrm{~kg}{ }^{-1}\right),{ }^{64} \mathrm{Ni}_{3} \mathrm{~S}_{2}$ nanorod arrays $\left(8.2 \mathrm{~W} \mathrm{~h} \mathrm{~kg}^{-1}, 214.6 \mathrm{~W} \mathrm{~kg}^{-1}\right){ }^{65} \mathrm{Ni}(\mathrm{OH})_{2} / / \mathrm{AC}$ (9.8 $\left.\mathrm{W} \mathrm{h} \mathrm{kg}^{-1}, 154 \mathrm{~W} \mathrm{~kg}{ }^{-1}\right),{ }^{66} \mathrm{NiCo}_{2} \mathrm{O}_{4} @ \mathrm{MnO}_{2} / / \mathrm{AC}\left(9.4 \mathrm{~W} \mathrm{~h} \mathrm{~kg}{ }^{-1}\right.$, $175 \mathrm{~W} \mathrm{~kg}^{-1}$ ), ${ }^{67} \mathrm{NiO} / /$ carbon (11 $\left.\mathrm{W} \mathrm{h} \mathrm{kg}{ }^{-1}, 500 \mathrm{~W} \mathrm{~kg}{ }^{-1}\right),{ }^{68}$ and $\mathrm{NiCo}_{2} \mathrm{~S}_{4} / / \mathrm{AC}\left(22.8 \mathrm{~W} \mathrm{~h} \mathrm{~kg}{ }^{-1}, 160 \mathrm{~W} \mathrm{~kg}^{-1}\right){ }^{69}$ Thus, the combined nickel hydroxide-nickel silicate exhibited an excellent electrochemical performance. To further investigate the electrochemical behavior of the prepared samples, EIS analysis on the HSC was carried out. Fig. S10 (ESI $\dagger$ ) shows the Nyquist plot of the HSC device in the frequency range of 0.01 to $100000 \mathrm{~Hz}$ and the simulated circuit used to elaborate the EIS. From the electrochemical impedance spectroscopy (EIS) results, it can be observed that the contact resistance is relatively small (about $0.8 \mathrm{Ohm}$ ), demonstrating the good conductivity. The semicircle in the middle frequency reveals the charge-transfer resistance originating from the faradaic reaction and EDLC. Besides, we also found that two asymmetric supercapacitor devices of $\mathrm{NiSi}-\mathrm{Ni}(\mathrm{OH})_{2}-4 / / \mathrm{AC}$ connected in series could light a blue light-emitting-diode for more than $100 \mathrm{~s}$, proving their practical applications (ESI, $\dagger$ Movie).

\section{Conclusion}

In summary, a hollow spherical nanostructured $\mathrm{NiSi}-\mathrm{Ni}(\mathrm{OH})_{2}$ composite was successfully prepared via a facile hydrothermal method. The application of silicon spheres as a hard template played a crucial role in the formation of the complex, leading to unique two-dimensional hollow spherical structures, which influenced its electrochemical properties. By simply tuning the nickel ion concentration in the reaction, a series of nickel silicate-nickel hydroxides was readily obtained. $\mathrm{NiSi}-\mathrm{Ni}(\mathrm{OH})_{2}$ exhibited a superior electrochemical capacitance $\left(476.4 \mathrm{~F} \mathrm{~g}^{-1}\right.$ at $2 \mathrm{~A} \mathrm{~g}^{-1}$ ), cycling stability (103.3\% capacitance retention over 10000 cycles) and rate performance. Furthermore, NiSi-Ni(OH $)_{2}$ also functioned as a high-performance positive material for HSC (capacitance of $674.7 \mathrm{mF} \mathrm{cm}{ }^{-2}$ with energy and power densities of 21.6 $\mathrm{W} \mathrm{h} \mathrm{kg}^{-1}\left(5.2 \mathrm{~mW} \mathrm{~h} \mathrm{~cm}{ }^{-3}\right)$ and $431.7 \mathrm{~W} \mathrm{~kg}^{-1}\left(104.3 \mathrm{~mW} \mathrm{~cm}^{-3}\right)$ with an average voltage of $1.6 \mathrm{~V}$, respectively). Our strategy may provide a promising approach for the design and synthesis of complex hollow structures with tailorable structures and compositions for high-energy and stable energy storage devices.

\section{Conflicts of interest}

There are no conflicts of interest to declare.

\section{Acknowledgements}

This work was partially supported by the National Natural Science Foundation of China (Grant No. 21771030, 21601026), Fundamental Research Funds for the Central Universities (DUT18RC(6)008) and the China Sponsorship Council (201806065025).

\section{References}

1 X. Lu, M. Yu, G. Wang, Y. Tong and Y. Li, Energy Environ. Sci., 2014, 7, 2160-2181.

2 P. Yang and W. Mai, Nano Energy, 2014, 8, 274-290.

3 F. Zhang, T. Liu, M. Li, M. Yu, Y. Luo, Y. Tong and Y. Li, Nano Lett., 2017, 17, 3097-3104. 
4 X. Zhao, R. Yu, H. Tang, D. Mao, J. Qi, B. Wang, Y. Zhang, H. Zhao, W. Hu and D. Wang, Adv. Mater., 2017, 29, 1700550.

5 T. Chen, Y. Tang, Y. Qiao, Z. Liu, W. Guo, J. Song, S. Mu, S. Yu, Y. Zhao and F. Gao, Sci. Rep., 2016, 6, 23289.

6 N. Hu, L. Zhang, C. Yang, J. Zhao, Z. Yang, H. Wei, H. Liao, Z. Feng, A. Fisher, Y. Zhang and Z. J. Xu, Sci. Rep., 2016, 6, 19777.

7 B. Liu, D. Tan, X. Wang, D. Chen and G. Shen, Small, 2013, 9, 1998-2004.

8 M. Chen, Y. Zhang, Y. Liu, Q. Wang, J. Zheng and C. Meng, ACS Appl. Energy Mater., 2018, 1, 5527-5538.

9 Y. Zhang, H. Jiang, Q. Wang and C. Meng, Chem. Eng. J., 2018, 352, 519-529.

10 T. Hu, Y. Liu, Y. Zhang, M. Chen, J. Zheng, J. Tang and C. Meng, J. Colloid Interface Sci., 2018, 531, 382-393.

11 J. Wang, H. Tang, L. Zhang, H. Ren, R. Yu, Q. Jin, J. Qi, D. Mao, M. Yang, Y. Wang, P. Liu, Y. Zhang, Y. Wen, L. Gu, G. Ma, Z. Su, Z. Tang, H. Zhao and D. Wang, Nat. Energy, 2016, 1, 16050.

12 S. Zhu, L. Li, J. Liu, H. Wang, T. Wang, Y. Zhang, L. Zhang, R. S. Ruoff and F. Dong, ACS Nano, 2018, 12, 1033-1042.

13 J. Zheng, Y. Zhang, T. Hu, T. Lv and C. Meng, Cryst. Growth Des., 2018, 18, 5365-5376.

14 Q. Jiang, N. Kurra, M. Alhabeb, Y. Gogotsi and H. N. Alshareef, Adv. Energy Mater., 2018, 8, 1703043.

15 J. Lin, H. Jia, H. Liang, S. Chen, Y. Cai, J. Qi, C. Qu, J. Cao, W. Fei and J. Feng, Adv. Sci., 2018, 5, 1700687.

16 J. Zhao, Z. Li, X. Yuan, Z. Yang, M. Zhang, A. Meng and Q. Li, Adv. Energy Mater., 2018, 8, 1702787.

17 Y. Zhang, J. Zheng, X. Jing and C. Meng, Dalton Trans., 2018, 47, 8052-8062.

18 J. Zheng, Y. Zhang, Q. Wang, H. Jiang, Y. Liu, T. Lv and C. Meng, Dalton Trans., 2018, 47, 452-464.

19 J.-N. Zhang, P. Liu, C. Jin, L.-N. Jin, S.-W. Bian, Q. Zhu and B. Wang, Electrochim. Acta, 2017, 256, 90-99.

20 M. Chen, J. Wang, H. Tang, Y. Yang, B. Wang, H. Zhao and D. Wang, Inorg. Chem. Front., 2016, 3, 1065-1070.

21 J. Wang, H. Tang, H. Ren, R. Yu, J. Qi, D. Mao, H. Zhao and D. Wang, Adv. Sci., 2014, 1, 1400011.

22 Y. Zhang, M. Chen, T. Hu and C. Meng, ACS Appl. Nano Mater., 2019, 2, 2934-2945.

23 J. Zheng, Y. Zhang, C. Meng, X. Wang, C. Liu, M. Bo, X. Pei, Y. Wei, T. Lv and G. Cao, Electrochim. Acta, 2019, 318, 635-643.

24 Y. Zhang, X. Jing, Y. Cheng, T. Hu and M. Changgong, Inorg. Chem. Front., 2018, 5, 2798-2810.

25 J. Yan, Z. Fan, W. Sun, G. Ning, T. Wei, Q. Zhang, R. Zhang, L. Zhi and F. Wei, Adv. Funct. Mater., 2012, 22, 2632-2641.

26 D. Li, X. Zhao, R. Yu, B. Wang, H. Wang and D. Wang, Inorg. Chem. Front., 2018, 5, 535-540.

27 H. Wang, H. S. Casalongue, Y. Liang and H. Dai, J. Am. Chem. Soc., 2010, 132, 7472-7477.

28 Z. Wu, X.-L. Huang, Z.-L. Wang, J.-J. Xu, H.-G. Wang and X.-B. Zhang, Sci. Rep., 2014, 4, 3669.

29 S.-M. Hao, J. Qu, Z.-S. Zhu, X.-Y. Zhang, Q.-Q. Wang and Z.-Z. Yu, Adv. Funct. Mater., 2016, 26, 7334-7342.
30 G. Zhan, C. C. Yec and H. C. Zeng, Chem. - Eur. J., 2015, 21, 1882-1887.

31 J. Chen, W.-J. Zhang, Z. Guo, H.-B. Wang, D.-D. Wang, J.-J. Zhou and Q.-W. Chen, ACS Appl. Mater. Interfaces, 2015, 7, 5373-5383.

32 X. Lai, J. Li, B. A. Korgel, Z. Dong, Z. Li, F. Su, J. Du and D. Wang, Angew. Chem., Int. Ed., 2011, 50, 2738-2741.

33 J. Wang, Y. Cui and D. Wang, Adv. Mater., 2018, 0, 1801993.

34 Y. Lu, L. Yu, M. Wu, Y. Wang and X. W. Lou, Adv. Mater., 2018, 30, 1702875.

35 Y. Wang, L. Yu and X. W. Lou, Angew. Chem., Int. Ed., 2016, 55, 14668-14672.

36 L. Yu, H. Hu, H. B. Wu and X. W. Lou, Adv. Mater., 2017, 29, 1604563.

37 X. Wei, C. Tang, X. Wang, L. Zhou, Q. Wei, M. Yan, J. Sheng, P. Hu, B. Wang and L. Mai, ACS Appl. Mater. Interfaces, 2015, 7, 26572-26578.

38 J. Zhu, C. Tang, Z. Zhuang, C. Shi, N. Li, L. Zhou and L. Mai, ACS Appl. Mater. Interfaces, 2017, 9, 24584-24590.

39 C. Tang, J. Sheng, C. Xu, S. M. B. Khajehbashi, X. Wang, P. Hu, X. Wei, Q. Wei, L. Zhou and L. Mai, J. Mater. Chem. A, 2015, 3, 19427-19432.

40 C. Tang, J. Zhu, X. Wei, L. He, K. Zhao, C. Xu, L. Zhou, B. Wang, J. Sheng and L. Mai, Energy Storage Mater., 2017, 7, 152-156.

41 Q. Wang, Y. Zhang, H. Jiang, X. Li, Y. Cheng and C. Meng, Chem. Eng. J., 2019, 362, 818-829.

42 Q. Wang, Y. Zhang, H. Jiang and C. Meng, J. Colloid Interface Sci., 2019, 534, 142-155.

43 Y. Cheng, Y. Zhang and C. Meng, ACS Appl. Energy Mater., 2019, 2, 3830-3839.

44 Q. Wang, Y. Zhang, H. Jiang, T. Hu and C. Meng, ACS Appl. Energy Mater., 2018, 1, 3396-3409.

45 Y. Zhang, C. Wang, H. Jiang, Q. Wang, J. Zheng and C. Meng, Chem. Eng. J., 2019, 375, 121938.

46 X. Liu, J. Wang and G. Yang, Chem. Eng. J., 2018, 347, 101-110.

47 W. Qiu, H. Xiao, M. Yu, Y. Li and X. Lu, Chem. Eng. J., 2018, 352, 996-1003.

48 R. D. White, D. V. Bavykin and F. C. Walsh, J. Mater. Chem. A, 2013, 1, 548-556.

49 L.-L. Xie, X.-Y. Cao, L.-X. Zhang, Z.-X. Dai and L.-B. Qu, Electron. Mater. Lett., 2013, 9, 183-186.

50 M.-C. Hsiao, C.-C. M. Ma, J.-C. Chiang, K.-K. Ho, T.-Y. Chou, X. Xie, C.-H. Tsai, L.-H. Chang and C.-K. Hsieh, Nanoscale, 2013, 5, 5863-5871.

51 C. Wan and B. Chen, Nanoscale, 2011, 3, 693-700.

52 Y. Wu, G. Chang, Y. Zhao and Y. Zhang, Dalton Trans., 2014, 43, 779-783.

53 C.-X. Gui, S.-M. Hao, Y. Liu, J. Qu, C. Yang, Y. Yu, Q.-Q. Wang and Z.-Z. Yu, J. Mater. Chem. A, 2015, 3, 16551-16559.

54 B.-H. Chen, Z.-S. Chao, H. He, C. Huang, Y.-J. Liu, W.-J. Yi, X.-L. Wei and J.-F. An, Dalton Trans., 2016, 45, 2720-2739. 55 A. Clearfield, Chem. Rev., 1988, 88, 125-148.

56 M. Liu, X. Wang, D. Zhu, L. Li, H. Duan, Z. Xu, Z. Wang and L. Gan, Chem. Eng. J., 2017, 308, 240-247. 
57 C. Qiu, J. Jiang and L. Ai, ACS Appl. Mater. Interfaces, 2016, 8, 945-951.

58 Z. Tang, C.-h. Tang and H. Gong, Adv. Funct. Mater., 2012, 22, 1272-1278.

59 H.-S. Kim, J. B. Cook, H. Lin, J. S. Ko, S. H. Tolbert, V. Ozolins and B. Dunn, Nat. Mater., 2016, 16, 454.

60 J. Wang, S. Dong, B. Ding, Y. Wang, X. Hao, H. Dou, Y. Xia and X. Zhang, Natl. Sci. Rev., 2017, 4, 71-90.

61 H. Inoue, Y. Namba and E. Higuchi, J. Power Sources, 2010, 195, 6239-6244.

62 P. Lin, Q. She, B. Hong, X. Liu, Y. Shi, Z. Shi, M. Zheng and Q. Dong, J. Electrochem. Soc., 2010, 157, A818-A823.

63 K.-W. Nam, K.-H. Kim, E.-S. Lee, W.-S. Yoon, X.-Q. Yang and K.-B. Kim, J. Power Sources, 2008, 182, 642-652.
64 S. Liang, J. Zhou, A. Pan, X. Zhang, Y. Tang, X. Tan, T. Chen and R. Wu, J. Power Sources, 2013, 228, 178-184.

65 J. Wen, S. Li, K. Zhou, Z. Song, B. Li, Z. Chen, T. Chen, Y. Guo and G. Fang, J. Power Sources, 2016, 324, 325-333.

66 S. T. Senthilkumar and R. Kalai Selvan, Phys. Chem. Chem. Phys., 2014, 16, 15692-15698.

67 M. Kuang, Z. Q. Wen, X. L. Guo, S. M. Zhang and Y. X. Zhang, J. Power Sources, 2014, 270, 426-433.

68 S.-L. Chou, J.-Z. Wang, J.-Z. Sun, D. Wexler, M. Forsyth, H.-K. Liu, D. R. MacFarlane and S.-X. Dou, Chem. Mater., 2008, 20, 7044-7051.

69 W. Kong, C. Lu, W. Zhang, J. Pu and Z. Wang, J. Mater. Chem. A, 2015, 3, 12452-12460. 